\title{
Complutum
}

ISSN: 1131-6993

\section{La protección del Paisaje Megalítico del río Gor (Granada). Criterios e instrumentos para la delimitación de una zona arqueológica territorial}

\author{
Antonio Manuel Montufo Martín ${ }^{1}$
}

Recibido: 12 de septiembre de 2019 / Aceptado: 7 de noviembre de 2019

Resumen. El artículo presenta los trabajos para la delimitación y protección administrativa del conjunto de necrópolis megalíticas del río Gor como Bien de Interés Cultural, defendiendo que supone un hito al trasladar al ámbito de la protección patrimonial la dimensión territorial y paisajística que tiene el megalitismo. Se repasa brevemente la historia de la protección del megalitismo en Andalucía, y se argumenta el rol fundamental que ha desempeñado el análisis territorial y paisajístico a la hora de proponer una extensa delimitación para el denominado "Paisaje Megalítico del río Gor". Junto a los criterios teóricos se ha empleado una metodología basada en el empleo sistemático de SIG para identificar las áreas de valor patrimonial a proteger.

Palabras clave: protección; paisaje; territorio; megalitismo; SIG; cuencas visuales.

[en] The protection for the megalithic landscape of the Gor river (Granada). Principles and methodology for delineating a territorial archaeological área

\begin{abstract}
The article presents the project for the delineation and administrative protection of the megalithic necropolis of the Gor river valley in Granada (Spain). The project constitutes a milestone by transferring to the scope of heritage protection the territorial and landscape dimension inherent to megalithic phenomenon. The paper briefly reviews the history of megalithic protection in Andalusia and analyzes the landscape and archaeological records presents in the Gor river valley. It also argues the fundamental role played by territorial and landscape analysis in proposing an extensive delimitation for the so-called "Gor River Megalithic Landscape". Together with the theoretical criteria, the methodology reinforces the territorial approach through the systematic use of GIS to identify the areas of heritage value to be protected.
\end{abstract}

Keywords: protection; landscape; territory; megaliths; GIS; viewshed analysis.

Sumario. 1. Introducción. 2. Megalitismo, territorio y paisaje. 3. La protección patrimonial de los sitios megalíticos en Andalucía. 4. El paisaje megalítico del río Gor: territorio, necrópolis y registro arqueológico. 5. Criterios para la delimitación de una zona arqueológica territorial. 6. Métodos e instrumentos para la delimitación de la zona arqueológica. 7. El BIC del paisaje megalítico del río Gor: protección y tutela. 8. Conclusiones. Agradecimientos. Bibliografía.

Cómo citar: Montufo Martín, A. M. (2019). La protección del Paisaje Megalítico del río Gor (Granada). Criterios e instrumentos para la delimitación de una zona arqueológica territorial. Complutum, 30 (2): 247-271.

\section{Introducción}

El objeto de este artículo es presentar el proyecto desarrollado por la Consejería de Cultura para la protección jurídica del conjunto de necrópolis megalíticas y demás sitios arqueológicos ubicados en el valle del río Gor y sus inmediaciones, en la provincia de Granada. Esta iniciativa ha permitido la protección conjunta del elenco de elementos patrimoniales a través de su inscripción en el Catálogo General del Patrimonio Histórico Andaluz como Bien de Interés Cultural (CGPHA en adelante) con la tipología de Zona Arqueológica, en un ejercicio pionero que ha permitido trasladar de forma plena al ámbito de la protección administrativa algunas de las claves que, desde el mundo de la investigación, se han identificado como determinantes a la hora de valorar un fenómeno arqueológico tan relevante como el megalitismo. 
En efecto, las investigaciones arqueológicas han identificado la territorialidad como uno de los elementos claves al analizar el megalitismo y consideran que la construcción de las grandes necrópolis megalíticas supone uno de los primeros y más notables ejercicios de socialización del espacio geográfico y de construcción de un paisaje simbólico por parte de las comunidades que habitaron dichos territorios. Sin embargo, estas perspectivas han tenido escasa presencia en la práctica tutelar, en la que ha primado, hasta fechas muy recientes, un enfoque monumentalista, centrado en la protección de las construcciones megalíticas y su entorno inmediato.

Con la protección del Paisaje Megalítico del río Gor se supera este enfoque, englobando en el ámbito protegido no sólo el conjunto de elementos arqueológicos, sino el territorio articulado por la sucesión de necrópolis, sitios arqueológicos y accidentes geográficos, salvaguardando así las relaciones de territorialidad que conformaron el paisaje ritual a lo largo de la prehistoria en esta región.

\section{Megalitismo, territorio y paisaje}

El megalitismo constituye una de las más tempranas y espectaculares manifestaciones arqueológicas relacionada con un valor tan singular como la territorialidad. Las construcciones megalíticas presentan una innegable dimensión espacial que va más allá de las funciones sociales y simbólicas asociadas al ritual funerario, principal contexto primigenio de uso de estas estructuras en Andalucía; esta faceta territorial es una de las claves que contribuyen a la pervivencia de los megalitos como referentes en el espacio geográfico, presentes de algún modo a lo largo de los tiempos.

Las formas arquitectónicas de las construcciones, su rotunda presencia y su localización en enclaves paisajísticos de gran relevancia invisten a los megalitos de numerosos valores simbólicos, haciendo de ellos un signo poderoso y duradero de la presencia, identidad y legitimación de la apropiación del territorio por las sociedades del pasado. El papel de los megalitos como marcadores territoriales pervive a lo largo de los tiempos, integrados en sucesivos contextos culturales que asignan a los megalitos nuevos usos y valores, sin perder por ello su innegable presencia en el territorio, lo que los convierte en hitos para establecer rutas, demarcaciones, referencias y topónimos (Martinón Torres, 2001).

Esta dimensión espacial del megalitismo ya fue intuida desde los albores de la investigación arqueológica y queda manifiesta en obras como la monografía de Georg y Vera Leisner (Leisner y Leisner, 1943), en la que el estudio territorial de las necrópolis y los análisis espaciales de distribución, mapas y planos desempeñan un papel fundamental. En la arqueología contemporánea, la valoración del megalitismo como fenómeno eminentemente territorial adquiere carta de naturaleza con la New Archaeology, destacando las aportaciones de Colin Renfrew (1973).

La presencia de los megalitos a lo largo de los territorios es una de las claves que explica los usos y reutilizaciones sucesivas de estas estructuras, a lo largo de los tiempos y bajo diferentes contextos culturales en los que estos monumentos adquieren nuevos valores y funciones. Este fenómeno, para el que se ha generalizado el empleo de la expresión "biografías de los monumentos", viene siendo tratado con especial interés en la bibliografía más reciente (entre otros Diaz Guardamino et al., 2015).

La construcción de los monumentos megalíticos supone la articulación de un paisaje primigenio, que evoluciona y se transforma al albur de los cambios en los contextos culturales. Entre los discursos que se identifican en la construcción de estos paisajes prehistóricos, David Wheatley y Patricia Murrieta apuntan a una serie de fenómenos, entre los que podemos citar la apropiación de sitios culturales y/o naturales en las construcciones megalíticas, que se materializa en el empleo para la construcción de la nueva estructura de grandes losas de piedra extraídas de canteras más o menos alejadas; la reutilización de menhires o estelas de construcciones megalíticas preexistentes; o la elección como lugar de emplazamiento de áreas en las que se venían desarrollando distintas manifestaciones culturales (Wheatley y Murrieta, 2009). 




Figura 1: los megalitos se integran en el singular paisaje del río Gor. Asomados al cañón del río, en la parte inferior de la imagen, al centro, se aprecian algunos de los dólmenes de la necrópolis del Llano de Olivares (Fuente: Excmo. Ayuntamiento de Gorafe)

Otros fenómenos que se identifican en el megalitismo europeo y que tienen que ver con la construcción de los paisajes incluyen el establecimiento de relaciones de visibilidad hacia el territorio en su conjunto o hacia determinados hitos territoriales; la intervisibilidad entre los sitios megalíticos o la vinculación de las necrópolis a las vías de paso y senderos. Junto a esto, la orientación de las sepulturas constituye otro de los rasgos que contribuyen a la construcción de un paisaje simbólico, marcando las posiciones de determinadas efemérides astronómicas o la preminencia de ciertos hitos paisajísticos.

En síntesis, la dimensión territorial y paisajística del megalitismo constituye uno de sus rasgos definitorios, y como tal es reconocida y valorada desde el ámbito de la investigación arqueológica. Sin embargo, tal y como discutiremos en el siguiente capítulo, el tratamiento e importancia otorgados a esta variable en el campo de la protección administrativa ha sido notablemente menor hasta fechas recientes.

\section{La protección patrimonial de los sitios megalíticos en Andalucía}

La historia de la protección jurídico-administrativa del patrimonio histórico, y del arqueológico en particular, muestra como los sitios megalíticos fueron objeto de especial atención desde los inicios de la tutela patrimonial. La monumentalidad de las sepulturas, en especial en los casos de grandes sepulcros como los de Antequera, motivó que destacasen entre el conjunto de yacimientos arqueológicos y fuesen objeto de pioneras medidas de protección administrativa, entre las que debemos citar la declaración del dolmen de Menga como Monumento Nacional en $1886^{2}$, una de las primeras actuaciones de protección del patrimonio histórico en Andalucía (Ruiz González, 2018).

La aprobación en 1911 de la primera ley específica para regular las actividades arqueológicas $^{3}$, en aquellos años limitada a la excavación, no conllevó el establecimiento de un régimen específico de protección para los yacimientos arqueológicos, que quedaban al amparo de las declaraciones como Monumento Nacional.

La promulgación del Real Decreto-Ley de 9 de agosto de 1926 sí tuvo implicaciones en el ámbito de la protección patrimonial, instaurando la figura del Monumento Histórico-Artístico ${ }^{4}$. Al amparo de esta norma va a tener lugar una de las más destacadas actuaciones de protección del patrimonio histórico en España, el emblemático Decreto de 3 de junio de 1931, en el que se protegen 789 inmuebles como Monumentos Histórico-Artísticos. El patrimonio megalítico recibe 
una singular atención en esta disposición administrativa, con la protección de diversos sitios megalíticos entre los que destacan los ubicados en Andalucía, como los dólmenes de Soto, La Pastora, Matarrubilla, El Gandul o El Romeral, así como la necrópolis de Los Millares.

La aprobación en 1933 de la Ley Relativa al Tesoro Artístico Nacional ${ }^{5}$ establece el marco jurídico para el patrimonio histórico español que se mantendrá vigente hasta 1985 . Sin embargo, y a pesar del largo tiempo de vigencia de la misma, el patrimonio megalítico apenas recibe atención desde el punto de vista de la protección administrativa hasta 1980. En ese año, debido a su estado de degradación, se incoan expedientes por vía de urgencia para la declaración como monumentos histórico-artísticos y arqueológicos de necrópolis como las de Fonelas, Los Eriales y Peñas de los Gitanos en Granada o las de Alcaide, Las Chaperas y el conjunto formado por El Moral, Los Gigantes y la Angostura en Málaga ${ }^{6}$.

La protección del patrimonio arqueológico megalítico se basa, a lo largo de gran parte del siglo XX, en sus valores monumentales y arquitectónicos, en un planteamiento monumentalista que entiende los megalitos como estructuras individuales, como sucede en el caso de las sepulturas de Antequera, para las que se establece una protección para cada una de ellas. La articulación de los megalitos en necrópolis recibe una atención menor, incluso en los casos anteriormente citados de Peñas de los Gitanos o Fonelas, en los que, a pesar de abordarse la protección conjunta de la necrópolis, no se resaltan como valores de estos bienes su articulación espacial o su carácter de conjunto. El estudio y valoración de las conexiones con el territorio, o del paisaje ritual articulado por los sitios megalíticos están, en la práctica, ausentes en estos momentos.

Sin embargo, y frente a este panorama, la investigación arqueológica venía identificando, desde los años 80, los componentes territoriales y paisajísticos del megalitismo como claves para su comprensión, estableciendo una nueva perspectiva a la que la práctica tutelar comenzará a acercarse en la última década del siglo $\mathrm{XX}$. Este acercamiento se ve favorecido por la promulgación de una nueva ley de patrimonio, la Ley 16/1985 de Patrimonio Histórico Español, que ofrece instrumentos normativos novedosos, como la figura del $\mathrm{BIC}$, en la que se reconoce la tipología específica de las Zonas Arqueológicas, o la del entorno de protección, que permiten empezar a reconocer desde el ámbito de la tutela patrimonial la vertiente territorial del megalitismo.

Así, algunas de las declaraciones de BIC realizadas en la década de los 90 del siglo XX abordan, aunque sea tímidamente, la protección del ámbito territorial articulado por las necrópolis megalíticas. Es el caso de la necrópolis de la Loma de Galera, en Alhama de Almería, en cuya declaración de BIC en $1993^{7}$ se establece, de forma pionera, una delimitación espacial que engloba las unidades geomorfológicas de asentamiento, si bien de forma restringida, y que se completa con un entorno de protección. No obstante, estas aproximaciones conviven con otras aún centradas en el enfoque monumentalista, que podemos ejemplificar con el caso de la necrópolis de Las Chaperas, en Casabermeja (Málaga), en el que la delimitación de la Zona Arqueológica se limita a un área circular de 100 $m$ de radio en torno a la estructura megalítica (la Figura 2 representa los distintos ámbitos de protección delimitados en estos expedientes).

En 2007, la declaración como BIC de las necrópolis de Gádor supone un nuevo avance, al delimitar la Zona Arqueológica como una sucesión de polígonos discontinuos que incluyen las crestas y cuerdas orográficas en las que se ubican las sepulturas megalíticas (ver Figura 2), alcanzado una superficie de 141 hectáreas ${ }^{8}$. Se protegen así no sólo las unidades geomorfológicas de asentamiento, sino también las relaciones territoriales y paisajísticas entre las distintas unidades de la necrópolis, si bien el territorio articulado por las mismas queda aún al margen de la protección administrativa.

En Andalucía, la promulgación en 2007 de la Ley 14/2007, de Patrimonio Histórico de Andalucía (LPHA en adelante), completa la evolución en el reconocimiento del territorio y el paisaje como elementos patrimoniales, tanto en el espíritu de la ley como en sus determinaciones normativas. Efectivamente, la exposición de motivos de la ley reconoce de forma explícita la "fuerte relación del patrimonio con el territorio", una visión del concepto de patrimonio que se traslada a la definición de la figura del BIC, para la que se establece una tipología específica, la de la Zona Patrimonial, como instrumento para la catalogación y protección de territorios de interés cultural y paisajístico. El nuevo marco normativo viene a culminar un proceso de reconocimiento, tanto de la dimensión espacial de los bienes culturales, como del propio territorio en cuanto elemento patrimonial, tema que hemos analizado recientemente (Montufo Martín, 2017a). 


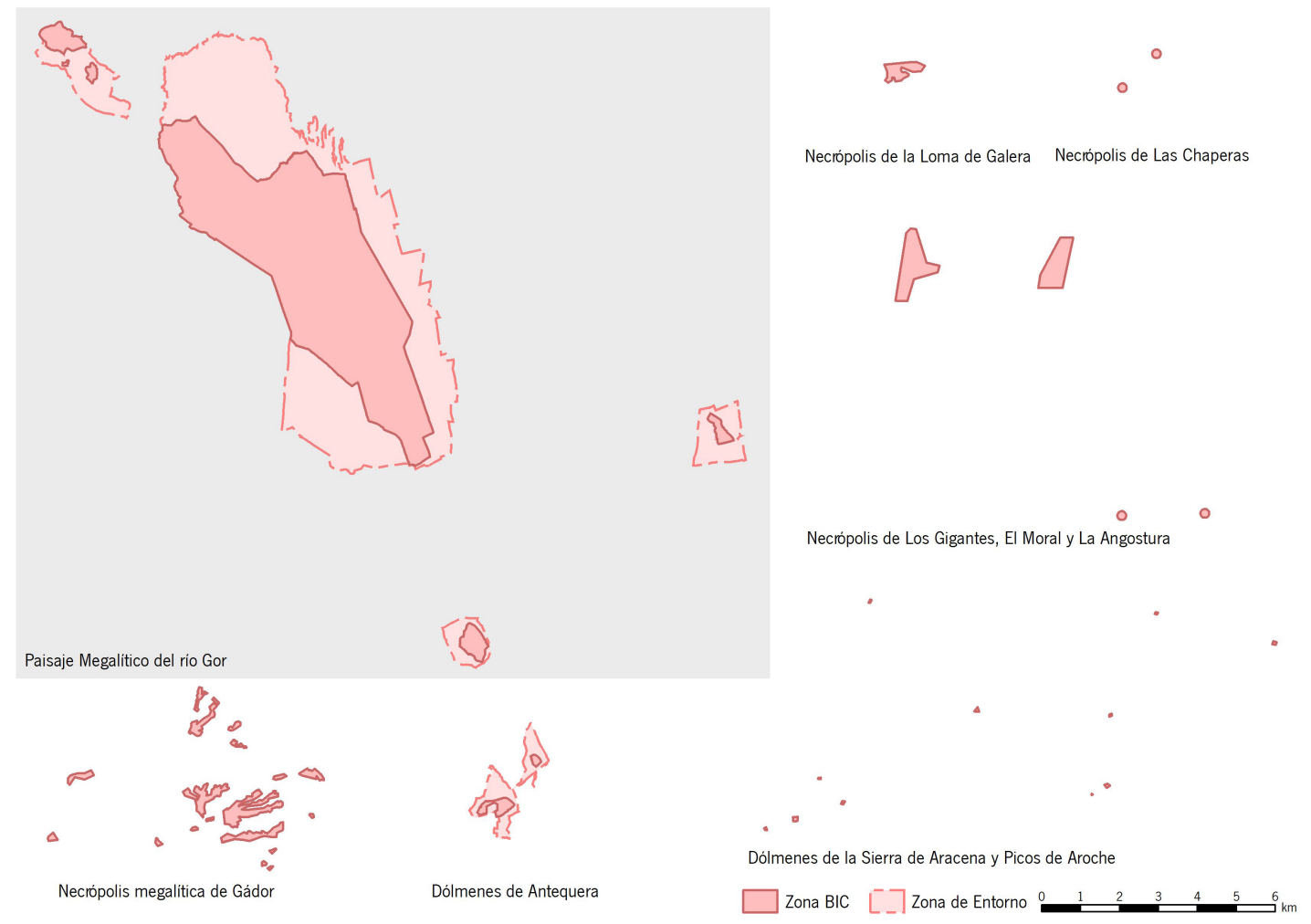

Figura 2: comparativa de las áreas protegidas de los sitios megalíticos citados en el texto. Todas las necrópolis representadas a la misma escala (Fuente: elaboración propia).

La inscripción en el CGPHA del Paisaje Megalítico del río Gor en 2018 supone la plena consagración del enfoque territorial y paisajístico para la catalogación del patrimonio arqueológico, plenamente justificado ante un caso paradigmático de íntima asociación entre los yacimientos arqueológicos y el espacio geográfico, que genera un paisaje cultural.

\section{El paisaje megalítico del río Gor: territorio, necrópolis y registro arqueológico}

El valle del río Gor constituye el enclave geográfico y eje vertebrador de uno de los complejos megalíticos más relevantes, no sólo de la península ibérica, sino del megalitismo europeo. La extraordinaria concentración de sepulturas, su articulación en extensas necrópolis con un variado patrón de asentamiento, la formalización arquitectónica de los megalitos y su interrelación con un territorio de gran singularidad paisajística hacen de este conjun- to un elemento patrimonial de primer orden. Junto a las sepulturas megalíticas, la ocupación prehistórica de este territorio se plasma en diversos asentamientos, que, sin embargo resultan aún poco conocidos, pudiendo señalar que en la actualidad existe una clara contraposición entre la potencia y la escala de las necrópolis y la escasa entidad y densidad de los asentamientos prehistóricos ${ }^{9}$.

El territorio objeto de este estudio se sitúa entre dos grandes unidades geográficas, la Sierra de Baza y el valle del Guadiana Menor, entre las que se desarrolla un extenso glacis (ver Figura 3). El río Gor ha excavado un valle que recorre transversalmente el glacis al pie de la sierra y que en su tramo central se muestra como un escarpado cañón fluvial que secciona el llano y genera desniveles de más de 150 $\mathrm{m}$, creando un impresionante relieve pleno de contrastes, como se ilustra en la Figura 4. Hacia el norte, conforme nos aproximamos al río Guadiana Menor, se desarrollan algunos de los relieves de badlands más espectaculares de la geografía peninsular. 


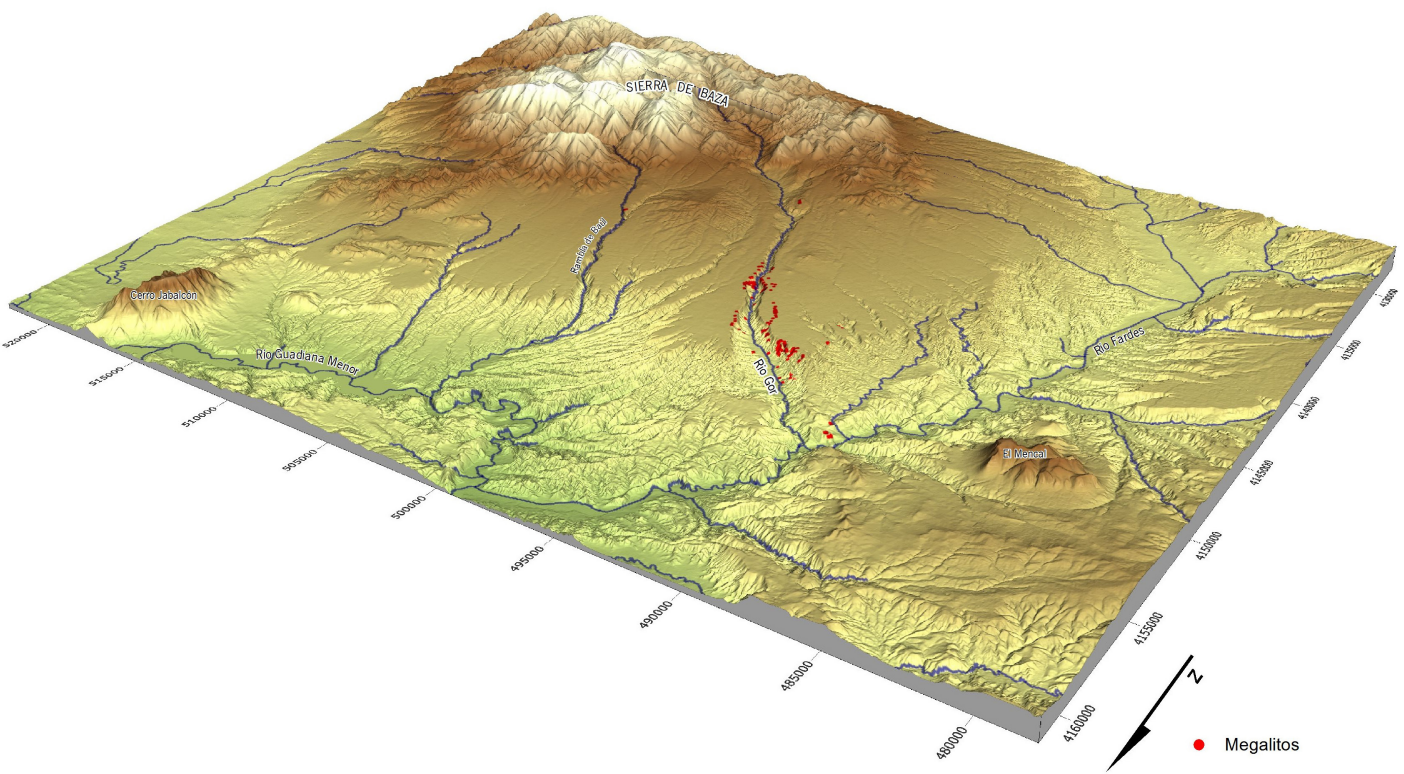

Figura 3: contexto regional de las necrópolis megalíticas. La vista 3D del MDT permite identificar las principales unidades geográficas y la estrecha relación entre las necrópolis megalíticas y el valle del río Gor (Fuente: elaboración propia).

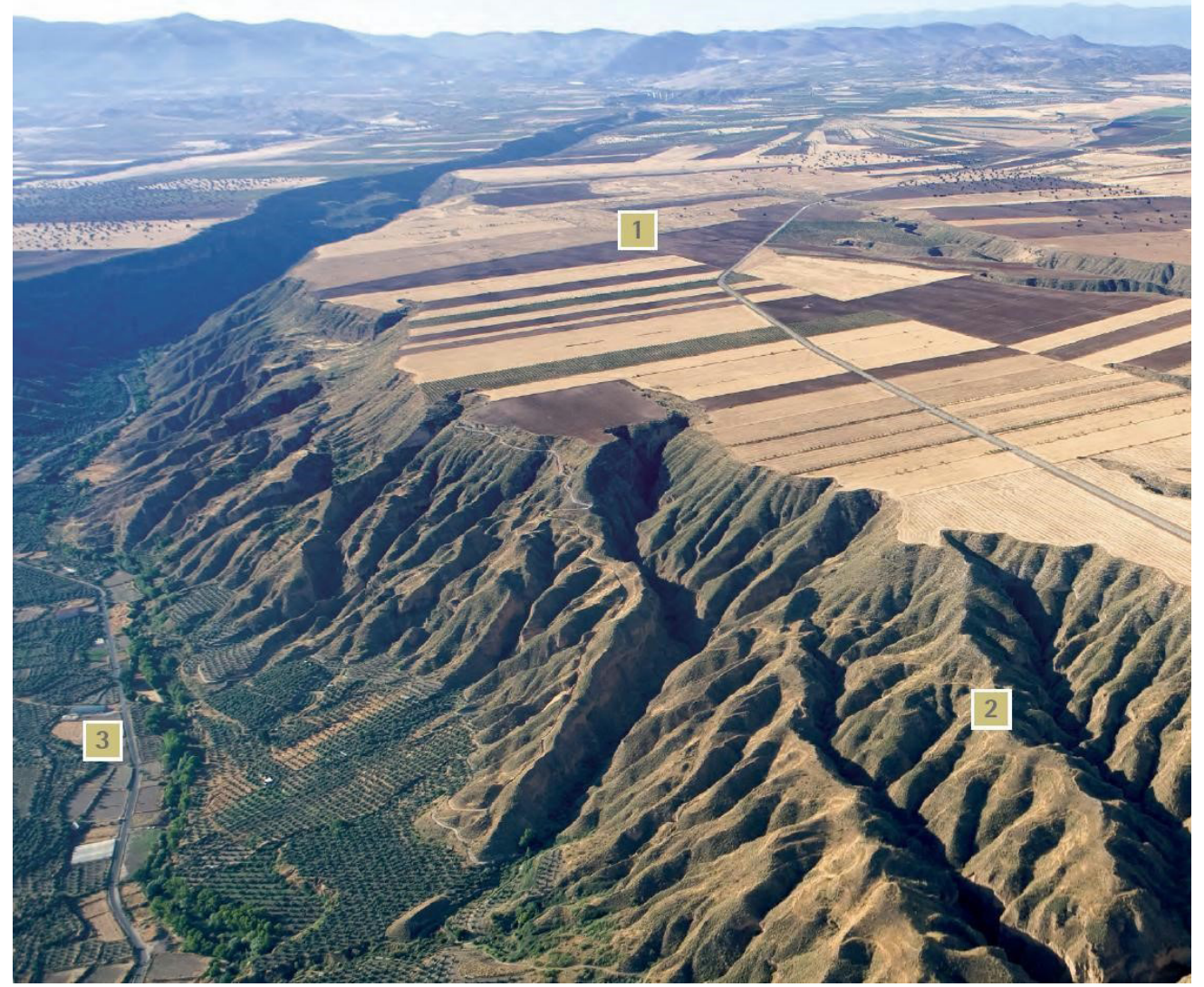

Figura 4: las unidades fisiográficas que definen el Paisaje Megalítico del río Gor son claramente identificables en esta foto aérea. Glacis (1), badlands y terrazas (2) y fondo de valle (3). La necrópolis de La Sabina ocupa las barranqueras marcadas con el número 2. Las texturas combinan el cultivo cerealístico, la vegetación esteparia semidesértica, los olivares, zonas de regadío y bosques galería (Fuente: De la Cruz et al., 2006). 
Las necrópolis megalíticas del río Gor son conocidas de antiguo y aparecen ya reseñadas en algunas de las obras pioneras de la arqueología prehistórica. Manuel de Góngora ya reconoció las concentraciones de dólmenes existentes y excavó algunos de ellos, como el de las Ascensias, actualmente identificado con el $\mathrm{n}^{\circ} 134$, dejando constancia de estos trabajos en sus "Antigüedades Prehistóricas de Andalucía" (Góngora y Martínez, 1868).

Sin embargo, serán los trabajos de Luis Siret y de Pedro Flores los que exhumarán una gran parte de los megalitos existentes en el valle, generando un volumen de información determinante para el desarrollo de las investigaciones posteriores; en concreto, los cuadernos de campo de Pedro Flores describen la excavación de 113 sepulturas entre 1891 y $1896^{10}$. Los datos recuperados fueron estudiados por Luis Siret con vistas al "Libro de las Sepulturas", trabajo que no acabó viendo la luz, como tampoco sucedió con "La España Prehistórica", que no obstante ha sido editado recientemente (Siret, 2001) y en el que se publican algunos de los materiales procedentes de estas necrópolis. No obstante, estos datos sirvieron de base para el estudio de Georg y Vera Leisner, Die megalithgräber der Iberischen Halbinsel: Der Süden", publicado en Berlín en 1943.

El matrimonio alemán analiza en su monumental monografía los datos recopilados por Siret y Flores, creando el primer corpus sistemático del megalitismo del sur peninsular, con un destacado enfoque territorial que se plasma en los mapas de distribución de sepulturas y en los análisis espaciales de las tipologías arquitectónicas y de distribución de determinados ítems del ritual funerario (ídolos, puntas de flecha, metal, etc.). En nuestra zona de estudio afirman haber identificado 95 de las 144 sepulturas originalmente excavadas por Luis Siret y Pedro Flores (Leisner y Leisner, 1943:85).

Tras años sin que se realicen trabajos de campo, Manuel García Sánchez y JeanChristian Spahni abordan entre 1955 y 1956 una campaña exhaustiva de reexcavación de las sepulturas identificadas por Siret, así como de otras inéditas, además de realizar una síntesis y cotejo de los datos anteriormente existentes. Como resultado, generan el catálogo más completo de las estructuras megalíticas de este conjunto (García Sánchez y Spanhi, 1959; García Sánchez, 1961); de acuerdo con sus datos, excavan 198 sepulturas, que sumadas a otras 40 localizadas por Siret y Flores que no consiguen identificar y dan por desaparecidas ${ }^{11}$, suman la cifra de 238 megalitos que integrarían el complejo megalítico del río Gor.

El trabajo de ambos investigadores no se limita a la excavación de los dólmenes, sino que abordarán otros yacimientos, como el asentamiento argárico del Cerro del Culantrillo en Gorafe (García Sánchez, 1963) o los grabados rupestres del Cerro de la Mina en Baños de Alicún (García Sánchez y Spanhi, 1958).

Tras esta fase, el interés por el conjunto megalítico decae sin que se produzcan actuaciones más allá de las recurrentes referencias presentes en los trabajos que abordan el megalitismo del sureste peninsular (Arribas Palau, 1960; Ferrer Palma, 1981; Molina González, 1983); asimismo, serán objeto de estudio por Michael Hoskin en el seno de sus investigaciones arqueoastronómicas (Hoskin et al., 1994). No será hasta finales del siglo $\mathrm{XX}$ cuando se reactiven las intervenciones sobre este patrimonio, de la mano de un ambicioso proyecto de adecuación para la visita pública y difusión, conocido como Parque Integral del Megalitismo (Castellanos et al., 2001; López y Castellanos, 2001; Manrique López, 2008).

El proyecto, financiado y ejecutado a través de la colaboración entre el Ayuntamiento de Gorafe, LÍDER Comarca de Guadix S.L., la Diputación Provincial de Granada y la Consejería de Cultura de la Junta de Andalucía, ponía el foco en potenciar el patrimonio histórico como factor de desarrollo económico y social. Los ejes del mismo fueron la adecuación de varias necrópolis para la visita, a través de la reexcavación de los megalitos y la creación de itinerario, con los correspondientes elementos de señalización, así como la construcción de un centro de interpretación en Gorafe. Si bien los resultados del Parque Integral del Megalitismo son evidentes desde el punto de vista de la difusión del conjunto patrimonial y la promoción del turismo cultural, en el ámbito de la investigación los trabajos realizados solo han supuesto una modesta aportación al conocimiento de estas necrópolis. 


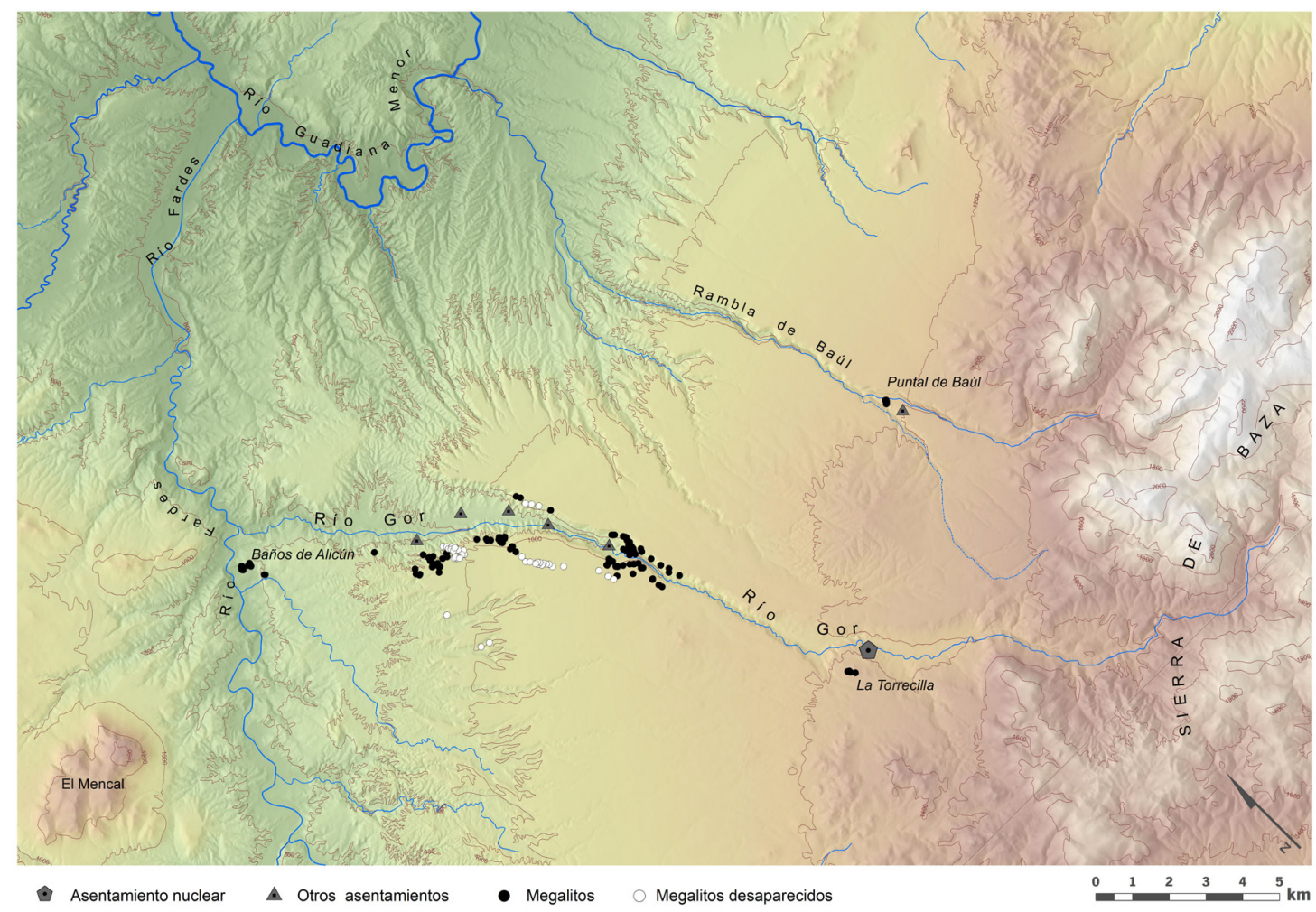

Figura 5: mapa general del valle del río Gor. Se aprecia la ubicación estratégica del valle para conectar la Sierra de Baza, de hasta $2000 \mathrm{~m}$. de altura con el río Guadiana Menor. Cartografía base: sombreado orográfico y colores hipsométricos. (Fuente: elaboración propia).

Con posterioridad, un equipo del Departamento de Prehistoria y Arqueología de la Universidad de Granada, del que he formado parte, ha realizado una serie de estudios parciales centrados en el análisis de la organización territorial del valle en época prehistórica (Afonso Marrero et al., 2006), la tipología de las sepulturas (Afonso Marrero et al., 2008), la continuidad de uso o la destrucción de megalitos en el siglo XX (Spanneda et al., 2014). Estas investigaciones suponen un avance en el conocimiento de algunos aspectos del conjunto arqueológico, si bien es cierto que la ausencia de trabajos de campo sistemáticos, de un proyecto general de investigación que integre los estudios realizados y de técnicas analíticas, en especial radiométricas, sobre los materiales recuperados en las excavaciones antiguas han lastrado los esfuerzos realizados.

En nuestros días se conservan al menos 155 sepulturas megalíticas (ver Figura 5), agrupadas en diez necrópolis que recorren el territorio, articuladas a lo largo del cauce del río y distribuidas por las terrazas que descienden desde el glacis, en el mismo borde de éste o en el llano. Junto al área nuclear conformada por el valle del río Gor, integran el conjunto megalítico tres enclaves geográficos secundarios, algo alejados del cañón fluvial, como son el Cerro de la Torrecilla, hacia el norte sobre el cauce del río, pero más próximo a la sierra de Baza; los Baños de Alicún, hacia el sur junto a la confluencia con el río Fardes; y el Puntal de la rambla de Baúl, a unos $7 \mathrm{~km}$ del valle, que responde al patrón de un espolón rocoso entre dos cauces fluviales.

En cuanto al emplazamiento de los megalitos, pueden distinguirse cuatro tipos básicos en el área nuclear: necrópolis relativamente dispersas en las cuerdas que, desde el fondo del valle, suben hasta el altiplano circundante (p. ej. la Cuesta de la Sabina); otras en las que los sepulcros se concentran en terrazas intermedias entre el glacis y el fondo del valle cercanas a los poblados (Hoyas del Conquín); aquellas localizadas 
en el "cejo" o borde del altiplano sobre el cañón del río (necrópolis de los Olivares); y por último, las que se distribuyen por el altiplano (necrópolis de los Llanos de la Gabiarra). Este patrón territorial marca rutas de desplazamiento tanto desde el fondo del río hasta el llano como hacia la sierra, conectando el Guadiana Menor, al norte, y la Sierra de Baza, al sur. El poblado de Las Angosturas, estratégicamente emplazado en el piedemonte de la Sierra de Baza al inicio del cañón del río Gor, ejercía el control territorial del acceso a la sierra y sus recursos (Afonso Marrero et al., 2006).

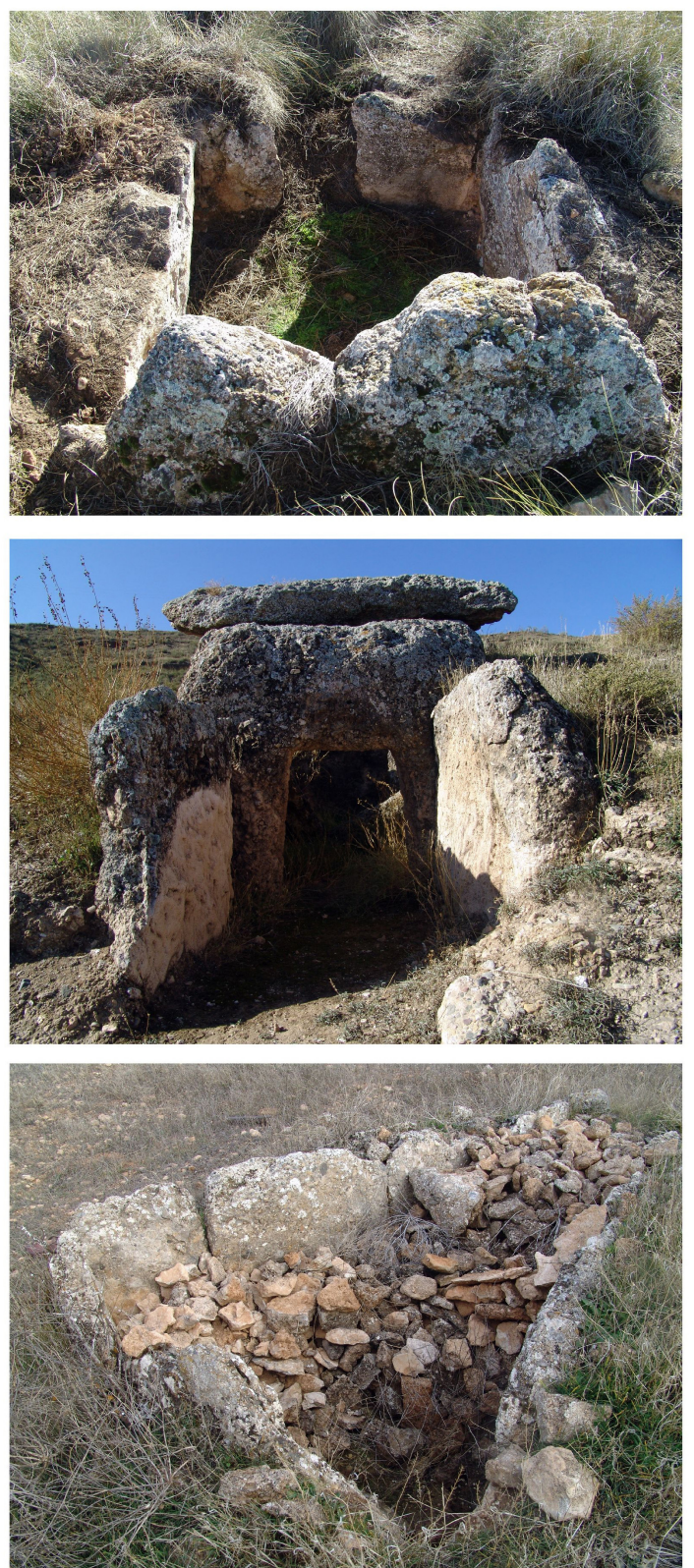

Figura 6: megalitos de las necrópolis del río Gor: de izquierda a derecha y de arriba abajo, dólmenes $\mathrm{n}^{\mathrm{0}}$ 004, 023, 067, 069, 083 y 097. Junto a aquellos mejor conservados y de mayor entidad arquitectónica, conviven otros en peor estado, algunos reutilizados como puestos de caza y majanos (Fuente: López Marcos y Cifuentes Martínez, 2011; elaboración propia). 
Los emplazamientos de las necrópolis en las áreas geográficas secundarias responden a otros patrones. Así, en el Puntal de Baúl la necrópolis se asienta en un espolón rocoso sobre la confluencia de dos ramblas, en el que se ha apuntado la presencia de un poblado prehistórico (Sánchez Quirante, 1990). En la necrópolis de la Torrecilla, las sepulturas se ubican en las laderas del cerro homónimo, mientras que en los Baños de Alicún las sepulturas se ubican en las terrazas de travertinos asociadas al manantial de Alicún de las Torres, sobre el cauce del río Fardes, en el que destaca la presencia de los paleocanales antrópicos de la acequia del Toril, que remarcan la importancia del agua en la ocupación de este enclave a lo largo de los tiempos.

A nivel cronológico, debemos señalar que, a pesar del número de tumbas excavadas, no se han publicado dataciones radiométricas de los materiales exhumados. El hecho de que el grueso de las excavaciones se realizará entre finales del siglo XIX y mediados del XX no es óbice para lamentar esta ausencia, máxime cuando las más recientes investigaciones sobre complejos megalíticos excavados de antiguo, como los de El Barranquete (Aranda Jiménez y Lozano Medina, 2014) o Churuletas, La Atalaya y Llano del Jautón (Aranda et al., 2018a), demuestran el potencial de estas dataciones para ilustrar la historia de estos monumentos, extendidas a lo largo de milenios. Con todo, se ha apuntado que las primeras sepulturas se erigirían entre finales del neolítico y principios del calcolítico (Manarqueoteca, 2001), perdurando su uso en el tiempo, como atestiguan los brazaletes de plomo y plata que indican su reutilización en el Bronce Final (Lorrio y Montero, 2004). La serie radiométrica obtenida en la necrópolis de Panoría (Darro), muy próxima tanto geográfica como tipológicamente, apunta a estas amplias secuencias de uso (Aranda Jiménez et al., 2018b).
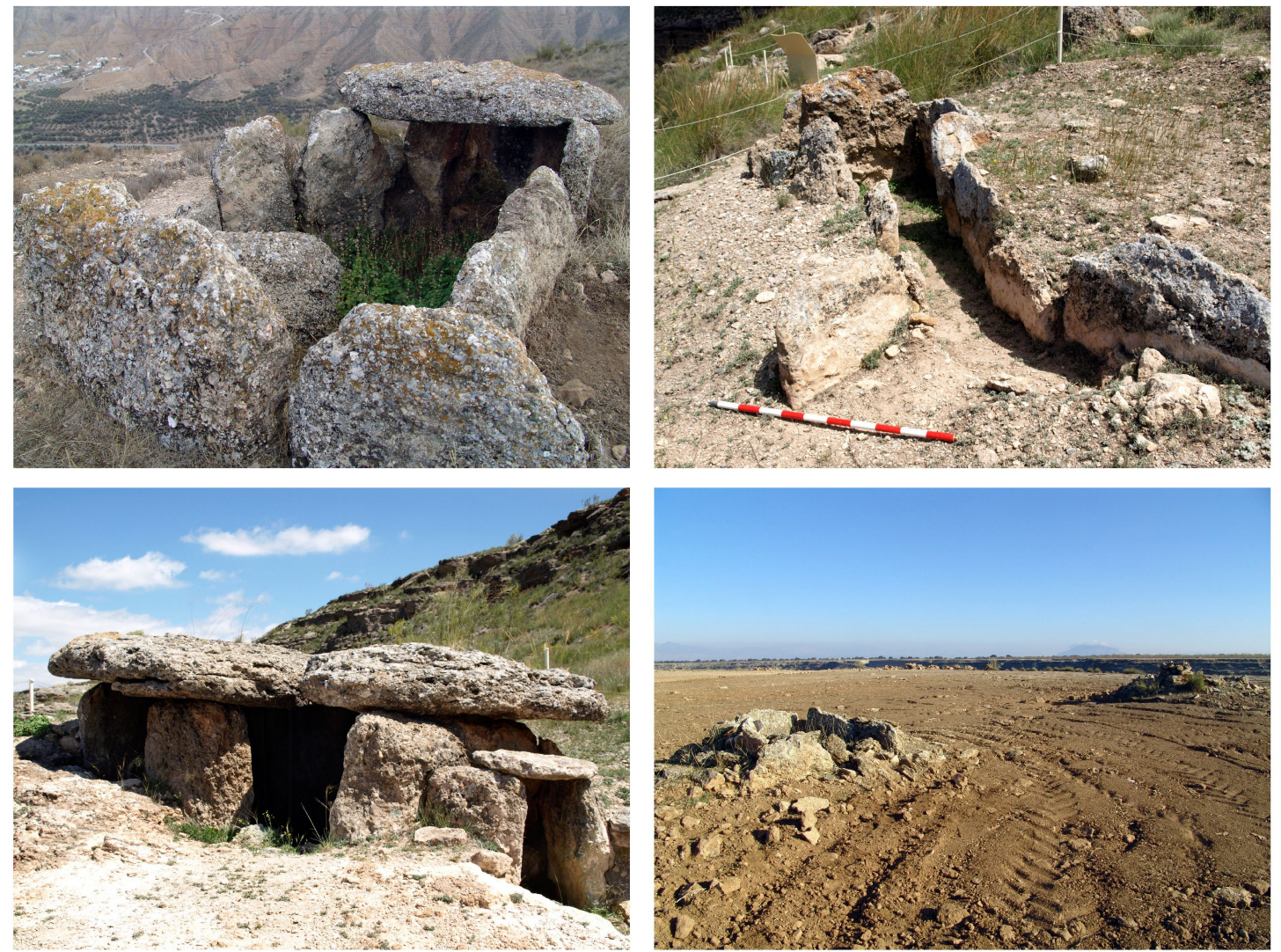

Figura 7: megalitos de las necrópolis del río Gor: de izquierda a derecha y de arriba abajo, dólmenes $\mathrm{n}^{\circ}$ 084, 132, 134 y 162. Los primeros destacan por su arquitectura, conservando cobijas de cubierta, puertas perforadas y atrios de entrada. La circulación de maquinaria agrícola junto a las estructuras arqueológicas deberá ser controlada (Fuente: López Marcos y Cifuentes Martínez, 2011). 
Se han propuesto diversas clasificaciones tipológicas para las tumbas, si bien el estudio sistemático realizado por el equipo de la UGR ha permitido establecer una tipología morfométrica a partir de los ángulos definidos por los encuentros entre los ortostatos de la cámara, distinguiendo dos grandes tendencias entre tumbas que presentan formas de ángulos marcados y cerrados y otras de formas más abiertas (Afonso Marrero et al., 2008). La distribución espacial de estas tipologías permite identificar asociaciones, como la concentración de las tumbas poligonales cerradas en áreas periféricas como el Puntal de Baúl o las trapezoidales en los Baños de Alicún. Los Leisner citan la presencia de varios tholoi en el área de la Torrecilla y en las proximidades de Las Angosturas (Leisner y Leisner, 1943), si bien a mediados del siglo XX ya no pudieron ser localizados (García Sánchez y Spanhi, 1959:85).

La conservación del complejo megalítico fue relativamente buena hasta mediados del siglo XX, como demuestra la pervivencia de unas 200 sepulturas; sin embargo, la mecanización agrícola posibilitó la roturación exhaustiva de los extensos llanos del glacis, desmontándose los ortostastos de los dólmenes y acumulándolos en montículos conocidos como majanos, algunos de ellos situados justo sobre estructuras arqueológicas (en la figura 3 se representa la ubicación aproximada de las sepulturas desaparecidas). Este proceso ha afectado especialmente a necrópolis como $\mathrm{La}$ Gabiarra, en la que ha desaparecido el $66 \%$ de las sepulturas identificadas por García Sánchez y Spahni, mientras que en otras como la del Cerrillo de las Liebres se conservan casi el 80\% de las estructuras existentes en 1955. Con todo, el conjunto de necrópolis del río Gor se ha conservado en mejores condiciones que las que podemos constatar en grupos cercanos como el de Fonelas, en el que se ha destruido un porcentaje muy superior de las sepulturas identificadas por los Leisner, o el de Los Eriales, desgraciadamente desaparecido en su práctica totalidad.

El registro arqueológico del río Gor se completa con un conjunto de sitios arqueológicos, si bien han recibido escasa atención en la literatura científica, donde apenas se citan los poblados del Cerro del Culantrillo (García Sánchez, 1963); Las Angosturas de Gor, de cuyas extensas excavaciones entre 1980 y 1983 apenas se ha publicado una breve nota (Botella López, 1980) y algunos materiales como el conjunto de ídolos recuperados (Escoriza Mateu, 1990); o el poblado de la Hoyas del Conquín, conocido sólo a través de prospecciones superficiales. Junto a estos, se conocen otros sitios como el Puntal del Cuervo, con una ocupación prehistórica sobre la que se superpone una fortificación y asentamiento amurallado medieval; los fortines de la Hoya del Conquín o la necrópolis tardoantigua de la Cuesta de Gor.

Más atención han recibido los grabados rupestres del Cerro de la Mina, que dominan el complejo de los Baños de Alicún (García Sánchez y Spanhi, 1958; Martínez García, 1995). Emplazados en la ladera sur del cerro, con una amplia cuenca visual, los petroglifos se ubican en cinco grandes bloques pétreos e incluyen elementos como círculos, cazoletas y canales, motivos soliformes, etc. Aparecen también motivos de época histórica, como cruces y signos alfabetiformes (Martínez García, 1995).

En síntesis, el registro arqueológico del río Gor testimonia una densa ocupación del territorio, de especial entidad en época prehistórica y con una excepcional representación de estructuras megalíticas, lo que unido a un espacio geográfico de gran singularidad y a la íntima asociación entre este y los yacimientos arqueológicos, en especial los dólmenes, genera un complejo patrimonial de primer nivel.

\section{Criterios para la delimitación de una zona arqueológica territorial}

Los criterios empleados en las delimitaciones de los Bienes de Interés Cultural de carácter territorial son diversos, y tienen que ver con aspectos como la localización geográfica de los elementos patrimoniales y su articulación espacial, la caracterización del territorio analizado o las relaciones de dominio visual que se establecen en dicho ámbito. En el caso del Paisaje Megalítico del río Gor, los criterios que guían la delimitación de los espacios protegidos han sido analizados y ponderados de forma explícita, estableciéndose seis elementos clave, cuyo análisis territorial conjunto permite trazar los límites de la Zona Arqueológica. 
1. La propia ubicación de los megalitos y demás sitios arqueológicos supone el primer y más relevante elemento de juicio para identificar y establecer la delimitación de los ámbitos protegidos. Los exhaustivos trabajos de campo, realizados en primera instancia por el equipo del Departamento de Prehistoria y Arqueología de la Universidad de Granada, en respuesta al encargo de la Delegación Territorial de Cultura de Granada, y completados y contrastados después por el inventario realizado por el Grupo de Desarrollo Rural de la comarca de Guadix, y las revisiones en campo realizadas por nosotros, han permitido establecer la ubicación precisa de las 155 estructuras megalíticas que han podido ser identificadas de forma inequívoca. Adicionalmente, se han localizado evidencias arqueológicas superficiales en varias zonas, si bien es cierto que los trabajos realizados hasta la fecha no pueden considerarse una prospección arqueológica formal y, por tanto, la información obtenida tiene un carácter preliminar.

2. La organización espacial de las sepulturas es otra de las variables analizadas, entendiendo que uno de los rasgos definitorios del megalitismo es su carácter de conjunto, en el que las sepulturas individuales se agrupan en necrópolis, conjuntos espacialmente articulados, claramente identificables aún a pesar de las diferencias que puedan existir a nivel interno en cuanto a la arquitectura y tipología, la cronología o los ajuares exhumados (ver figura 8).

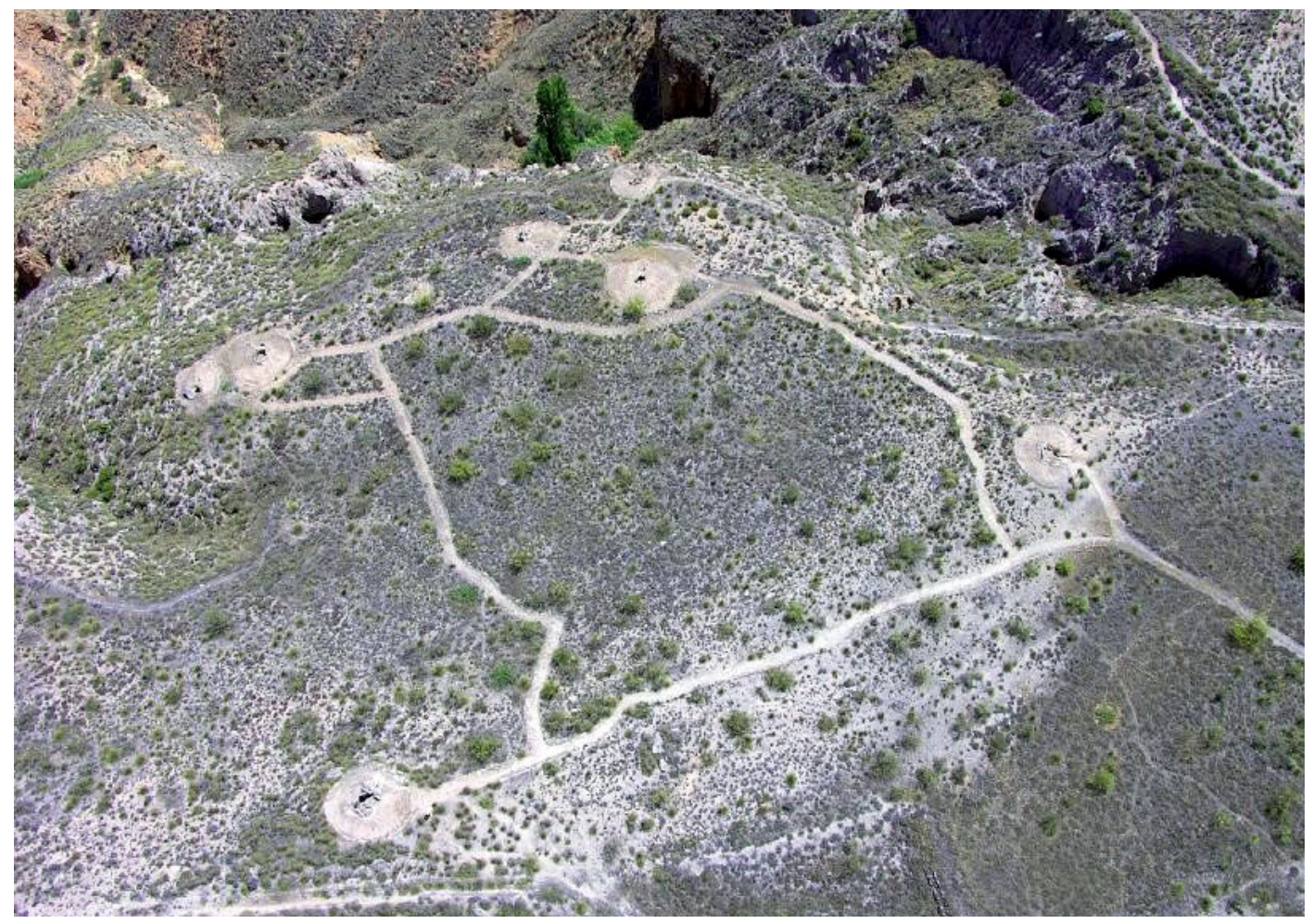

Figura 8: vista aérea de la necrópolis de Las Majadillas (Fuente: López Marcos y Cifuentes Martínez, 2011).

En el caso de las necrópolis del río Gor, la articulación del conjunto en varias necrópolis fue reconocida tanto por Luis Siret como por Georg y Vera Leisner, pero fue el detallado estudio de García Sánchez y Spahni el que estableció la relación de necrópolis más conocida (García Sánchez y Spanhi, 1959), ampliamente citada en la bibliografía científica. Sin embargo, en el transcurso de este proyecto hemos podido comprobar que no es posible mantener hoy en día la identificación de algunas de estas agrupaciones, ya que la desaparición de un notable número de sepulturas ha desarticulado la organización espacial que pudieron reconocer ambos investigadores; tal es el caso de las necrópolis del Llano de Olivares y del Llano de Carrascosa, ubicadas en el borde del cañón, y para las que el análisis espacial realizado impide corroborar las posibles diferencias entre am- 
bas, ya que presentan una continuidad geográfica sin concentraciones espacialmente significativas (Figura 9). A esto se añaden otras circunstancias como las transformaciones del parcelario y cubiertas de suelo o la pérdida de la microtoponimia ${ }^{12}$.

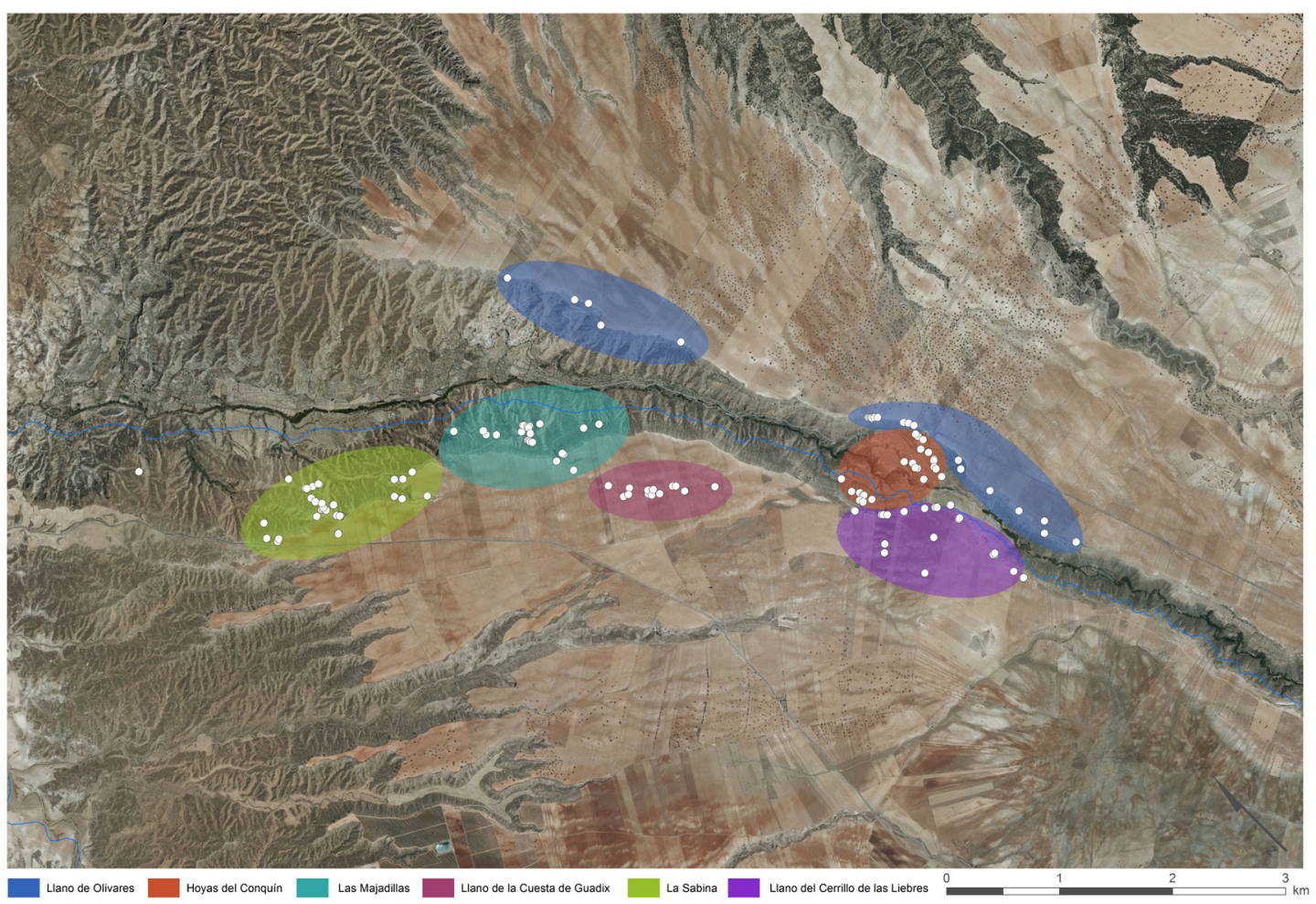

Figura 9: necrópolis existentes en el área nuclear del valle del río Gor. Los megalitos existentes se representan con puntos blancos. Cartografía base: Ortofotos PNOA máxima actualidad (Fuente: elaboración propia).

3. Los emplazamientos geográficos de los yacimientos arqueológicos constituyen un elemento con un valor intrínseco en la caracterización de los mismos; así ha sido reconocido en el campo del análisis y la interpretación arqueológica desde la acuñación del concepto de la Unidad Geomorfológica de Asentamiento o UGA (Nocete Calvo, 1996). Atendiendo a la casuística presente en el valle del río Gor, las necrópolis megalíticas se asientan en unidades geomorfológicas claramente definidas y singulares, como los bordes del glacis que se asoman al cañón, las mesetas que se intercalan entre las laderas abarrancadas que descienden desde el llano al cauce del río o los extensos llanos. Desde un punto de vista patrimonial, el emplazamiento de las necrópolis y sitios arqueológicos constituye un elemento cualificador que añade valores patrimoniales más allá de los históricos y arqueológicos, convirtiéndose en otro de los elementos a considerar a la hora de identificar los ámbitos que deben ser protegidos.

4. El análisis de las relaciones de intervisibilidad y dominio visual del territorio es uno de los aspectos que más ha evolucionado en la investigación del megalitismo en los últimos años. La introducción de la tecnología de los Sistemas de Información Geográfica (SIG en adelante) ha permitido calcular de forma automatizada y cuantitativa las cuencas visuales desde un punto dado, y esta capacidad ha sido ampliamente explotada para el estudio del megalitismo.

En Andalucía, el estudio del dominio visual del megalitismo mediante SIG cuenta con una notable presencia en la bibliografía, destacando los trabajos desarrollados en la Andalucía occidental, en complejos como los de Sierra Morena (García Sanjuán et al., 2006 y 2009; Wheatley et al., 2010; 
Murrieta Flores et al., 2011; Murrieta Flores, 2014) o la campiña cordobesa (Martín de la Cruz et al., 2004). Otras áreas de Andalucía presentan un menor desarrollo de este tipo de análisis, si bien pueden citarse los estudios realizados en necrópolis tan emblemáticas como las Peñas de los Gitanos en Montefrío (Montufo Martín et al., 2010, 2011), los conjuntos hipogéicos del poniente granadino (Montufo Martín et al., 2010) o Antequera (García Sanjuán et al., 2016).
En el caso de nuestro proyecto, el estudio de la visibilidad desde y hacia los megalitos cobra especial relevancia por una doble confluencia de factores: de un lado, la importancia que la investigación arqueológica atribuye al dominio visual como elemento clave para entender el megalitismo; por otro lado, el hecho de que estas relaciones de intervisibilidad se desarrollan en un espacio geográfico de gran personalidad y singularidad paisajística, lo que cualifica los valores históricos y arqueológicos del conjunto (Figura 10).

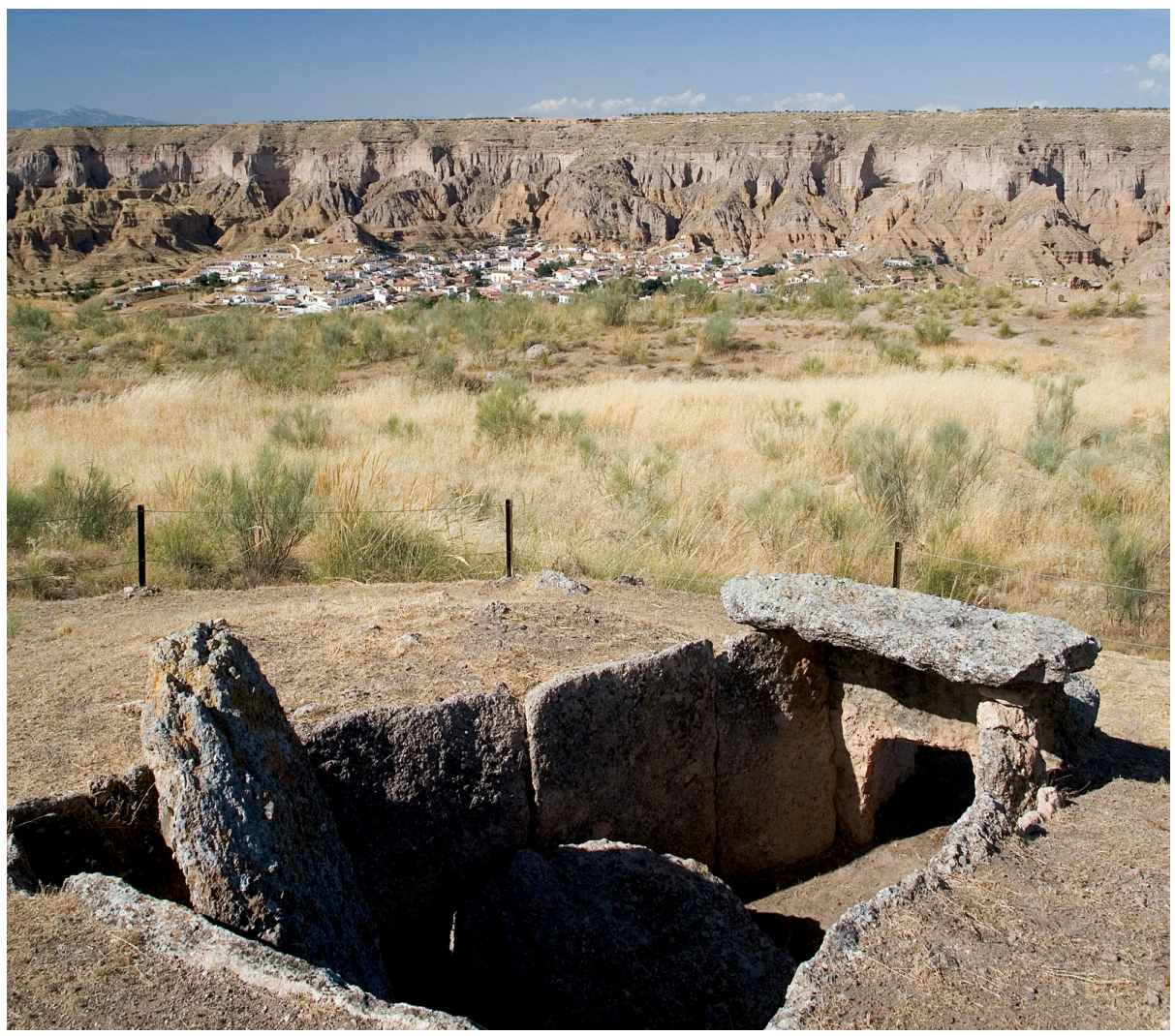

Figura 10: vista del altiplano y el cañón del río Gor desde el dolmen 69, en la necrópolis de Las Majadillas (Fuente: Excmo. Ayuntamiento de Gorafe).

5. El criterio de proximidad ha desempeñado un rol de cierta importancia a la hora de fijar límites precisos para el BIC y su entorno, que resultasen a la vez relevantes a nivel patrimonial y operativos para la tutela efectiva del espacio protegido. Como he comentado con anterioridad, el análisis de las cuencas visuales acumuladas permite zonificar el territorio en función de su visibilidad, pero estas zonas de dominio visual se extienden notablemente en algunas partes del territorio analizado, en especial en la zona de los llanos, donde la ausencia de elemen- tos topográficos u orográficos que limiten la visibilidad o puedan ser empleados para fijar un límite claro ha hecho que se emplee como criterio de delimitación la definición de una zona de protección mínima de 250 o $500 \mathrm{~m}$. de radio desde las sepulturas.

6. El último criterio empleado es el análisis del parcelario catastral y demás entidades topográficas, que permiten establecer la delimitación "fina" del BIC y su entorno de protección, trazando de forma precisa los límites de la misma en base a la presencia de elementos topográficos que sirviesen como 
elemento delimitador (carreteras, caminos, ramblas o cuerdas orográficas) de las zonas identificadas como poseedoras de los valores que se protegen en esta Zona Arqueológica. Las parcelas catastrales han desarrollado idéntica función en los casos en los que las entidades topográficas no han podido ser aplicadas.

\section{Métodos e instrumentos para la delimitación de la zona arqueológica}

Los criterios anteriormente enunciados otorgan un peso dominante a la perspectiva territorial, por lo que desde un primer momento fue patente la necesidad de implementar un SIG que permitiera el análisis conjunto de los diversos factores que debían justificar la delimitación del ámbito a proteger. En consecuencia, se ha procedido a recopilar diversas fuentes cartográficas que facilitasen la adecuada representación y caracterización del territorio analizado.

Entre las más relevantes está la Ortofotografía Pancromática de Andalucía 1956, elaborada a partir del conocido como Vuelo Americano serie B, realizado por la fuerza aérea estadounidense. Esta serie cartográfica constituye la más temprana representación fotogramétrica sistemática del territorio andaluz ${ }^{13}$, y además de ofrecer una visión directa del territorio tal y como aparecía a mediados del siglo XX, puede integrarse en el SIG como ficheros cartográficos georreferenciados.

Otro elemento básico para el análisis territorial realizado ha sido el Modelo Digital del Terreno (MDT), elaborado por el Instituto de Cartografía y Estadística de Andalucía (IECA), con una resolución de $10 \mathrm{~m}$., a partir del cual hemos generado productos como el sombreado orográfico o el mapa de tintas hipsométricas, cuyo uso combinado permite una atractiva visualización de la orografía del territorio analizado, que además resulta claramente legible a la hora de valorar el relieve y los accidentes orográficos.

Otros elementos integrados en el SIG incluyen ortofotografías producidas por el IECA en diversas fechas, la cartografía catastral vectorial, y cartografía topográfica básica a varias escalas, producida por el IECA.

La cartografía de elementos patrimoniales consiste en el inventario georreferenciado de dólmenes y otros sitios arqueológicos, que emana en primer lugar del trabajo realizado por el equipo de la UGR; información que hemos contrastado con el inventario realizado por el Grupo de Desarrollo Rural de la Comarca de Guadix, y con los trabajos de campo y el análisis de fotointerpretación y fuentes cartográficas desarrollado por nosotros. Asimismo, se han integrado en el SIG los planos elaborados por García Sánchez y Spanhi, una vez georreferenciados a partir de la Ortofotografía Pancromática de Andalucía 1956.

La integración de estas fuentes cartográficas en el SIG, en especial las ortofotografías aéreas y el MDT, ha permitido obtener una primera zonificación del territorio analizado, identificando y cartografiando las principales unidades geomorfológicas que constituyen el soporte para este paisaje cultural. Estas actúan como elementos estructurantes del paisaje e incluyen tres unidades básicas: el llano o glacis, cuyo borde o cejo adquiere un protagonismo singular por la destacada presencia de sepulturas megalíticas; las laderas del cañón, verticales y escarpadas hacia el sur y suavizadas hacia el norte en una sucesión de barrancos y cárcavas; y las zonas llanas del fondo del valle, que adquieren mayor desarrollo conforme el cañón se abre en su recorrido hacia el sur. Este conjunto se completa con los extensos badlands que se desarrollan en la zona nororiental del territorio, conocidos como badlands de BácorOlivar.

Un paso adicional en cuanto a técnicas de análisis mediante SIG viene dado por el estudio de la visibilidad y la percepción del territorio desde los sitios arqueológicos, campo en el que la introducción de estos sistemas ha supuesto una auténtica revolución que ha generado una bibliografía ingente. Desde las primeras aproximaciones, basadas en el cálculo automatizado del área visible desde un punto dado, esta línea de análisis ha experimentado un notable desarrollo, avanzando en una visión menos mecanicista, a more humanistic perspective (Fábrega-Álvarez y Parcero-Oubiña, 2019:2), en la que se integran y desarrollan nuevas modalidades y conceptos como los visualscapes, la fragmentación de cuencas visuales y horizontes de visibilidad, los visibility fields o el concepto de Individual Distance Viewshed (Fábrega-Álvarez y Parcero-Oubiña, 2019) 





En el caso de nuestro proyecto, hemos realizado un análisis de cuencas visuales acumuladas, frecuentemente citado como CVA (Cumulative Viewshed Analysis), y que cuenta con una larga trayectoria en la investigación del megalitismo desde los trabajos pioneros de Clive Ruggles (Ruggles et al., 1993) y, fundamentalmente, David Wheatley (1995 y 1996). La técnica se basa en el cálculo de cuencas visuales desde una serie de puntos, en este caso desde el conjunto de megalitos, identificando el área visible desde cada uno de ellos, para, con posterioridad, realizar la suma de todas las cuencas calculadas, obtenido así una cartografía ráster en la que cada pixel indica el número de puntos, en este caso megalitos, desde los que resulta visible dicha porción de terreno.

El CVA constituye una aportación básica en nuestro estudio, identificando los ámbitos territoriales más relevantes y perceptibles desde los megalitos, y permitiendo así realizar una zonificación del territorio en función de su relevancia visual (ver Figura 11). Los datos del análisis demuestran como la totalidad del espacio geográfico era dominado desde las sepulturas, emplazadas en hitos orográficos relevantes. Este paisaje visual (Llobera, 2006) enfatiza algunos de los elementos que definimos como estructurantes del mismo, como los cejos o bordes del glacis.

Otro de los resultados que aporta el CVA es confirmar la importancia del área de badlands de Bácor-Olivar en este paisaje visual, una zona que a priori parece secundaria frente al gran eje que define el cañón del río, y que, sin embargo, muestra una alta visibilidad desde las sepulturas (Figura 12), lo que justifica su inclusión dentro del ámbito protegido.

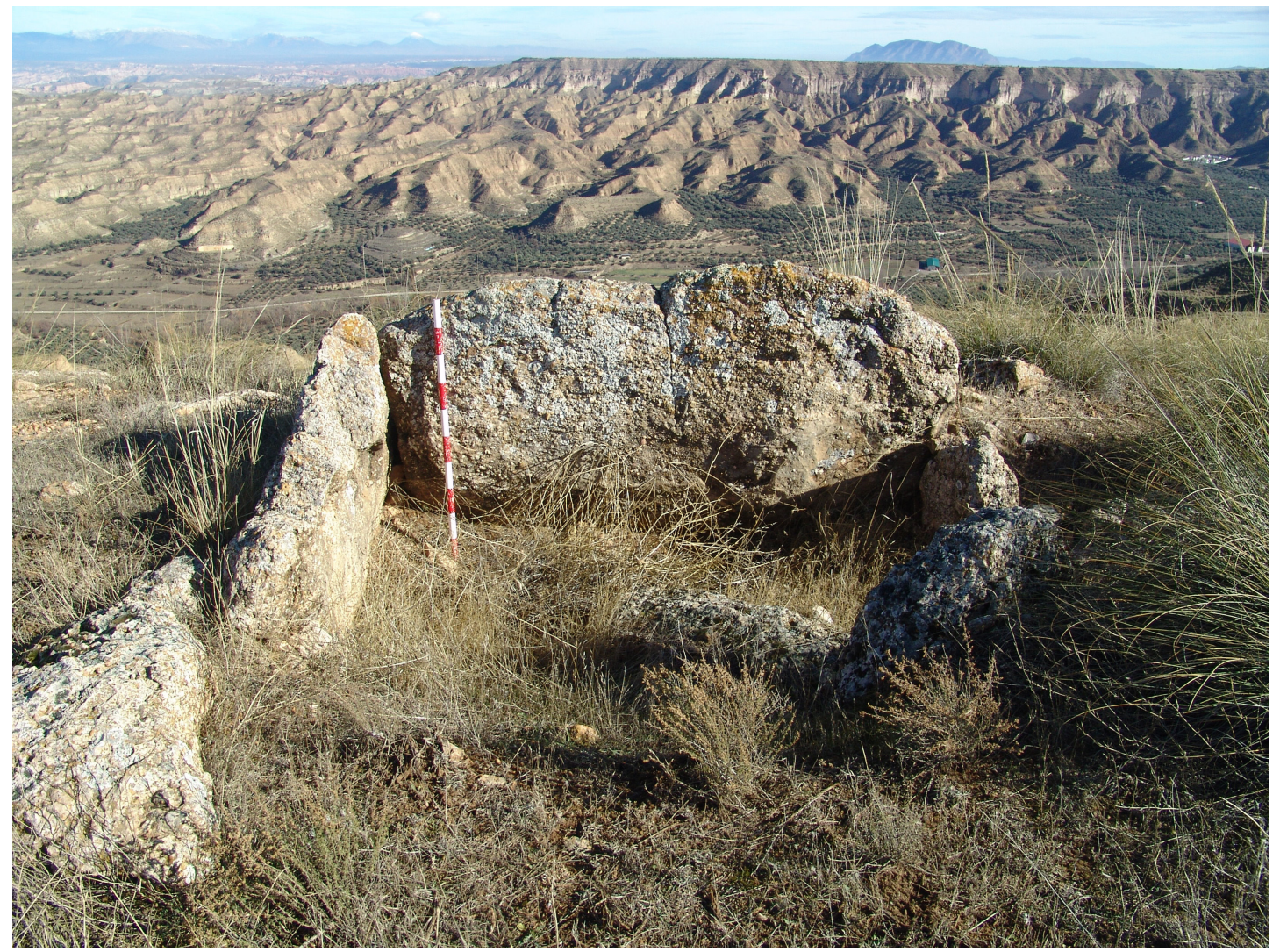

Figura 12: la cuenca visual desde el dolmen 24 se extiende hacia los badlands de Bácor-Olivar. El análisis de cuencas visuales ha demostrado la relevancia de esta unidad geográfica en el dominio visual desde los megalitos (Fuente: López Marcos y Cifuentes Martínez, 2011).

El análisis conjunto de los emplazamientos de las necrópolis y asentamientos, y de la zonificación visual establecida por el CVA permite una primera identificación de las áreas de in- terés patrimonial, potencialmente integrables en la delimitación del espacio protegido. Sin embargo, esta primera identificación debe ser tamizada por otros criterios como la relevancia 
y proximidad a los elementos patrimoniales nucleares, o la existencia de elementos topográficos en el territorio que permitan establecer de forma precisa los límites concretos de las áreas protegidas.

En esta segunda fase de concreción, se han analizado tanto la distribución de los límites parcelarios como la presencia de otros hitos topográficos, como caminos, antiguas lindes fosilizadas en el terreno, etc. Otra de las variables que hemos considerado es la de proximidad a los megalitos, en especial en las zonas del glacis, en las que las cuencas visuales se extienden de forma notable por el llano, por lo que resulta adecuado fijar unos límites precisos para el bien, de cara tanto a la protección efectiva del mismo, garantizando la ausencia de alteraciones que de forma directa afecten a sus valores patrimoniales, como a su tutela y gestión.

La aplicación de este segundo bloque de criterios ha implicado la realización de un análisis de proximidad, estableciendo áreas de proximidad (buffer) a distancias de $250 \mathrm{y}$ $500 \mathrm{~m}$. de radio desde las sepulturas megalíticas, y de un estudio integrado del parcelario y los hitos topográficos en relación con estas áreas de proximidad y demás elementos considerados (localización de yacimientos arqueológicos, megalitos y áreas de dominio visual).

\section{EI BIC del paisaje megalítico del río Gor: protección y tutela}

El resultado de este análisis, que podemos caracterizar como multivariante, ofrece los fundamentos para delimitar el área a proteger, integrada por las zonas que se califican como Bien de Interés Cultural, en su tipología de Zona Arqueológica, y por aquellas que se adscriben como entorno de protección del mismo.

El procedimiento administrativo para la protección del Paisaje Megalítico del río Gor ha seguido la tramitación establecida por la ley andaluza de patrimonio histórico, que contempla la participación de la ciudadanía y otros agentes afectados en varias fases. Los ayuntamientos y otros organismos oficiales que puedan verse afectados son consultados de forma expresa, mientras que para el resto de la ciudadanía hay un periodo de información pública. Esta participación se complementa, gracias a las leyes de transparencia, con la publicación en el Portal de la Transparencia de la Junta de Andalucía de toda la documentación del expediente, de forma que cualquier ciudadano puede consultar y participar en el procedimiento.

Somos conscientes de que la regulación actualmente vigente debe mejorar las fórmulas de participación en estos procesos administrativos, en línea con las políticas de gobierno abierto, transparencia y participación ciudadana que se impulsan en el ámbito de las administraciones públicas; en el sector del patrimonio histórico, textos internacionales como la Convención de Faro de 2005, del Consejo de Europa, abogan por impulsar este enfoque participativo. No obstante, en el caso de este BIC, debemos resaltar la implicación de las administraciones locales, y la concienciación de la población con la protección de este patrimonio, que ya se manifestó con la cesión de parcelas privadas para el desarrollo de las actuaciones de puesta en valor de las necrópolis que integran el Parque Integral del Megalitismo.

La inscripción formal del BIC en el Catálogo General del Patrimonio Histórico Andaluz, y en consecuencia en el Registro General de Bienes de Interés Cultural del Ministerio de Cultura y Deporte, se produce mediante el Decreto 43/2018, del Consejo de Gobierno de la Junta de Andalucía ${ }^{14}$. El BIC del Paisaje Megalítico del río Gor queda organizado en cuatro grandes áreas (ver Figura 13), una de carácter nuclear y gran extensión, articulada alrededor del tramo medio del valle del río Gor, y otras periféricas, de menor entidad geográfica y que protegen elementos en ámbitos que no tienen la suficiente continuidad geográfica con el área nuclear. La zona delimitada en el área nuclear es continua y homogénea, albergando de forma global el territorio articulado por el conjunto de necrópolis y sitios arqueológicos, y convirtiéndolo en elemento patrimonial en sí mismo. Las relaciones territoriales y paisajísticas establecidas hacia ámbitos como los badlands de Bácor-Olivar se salvaguardan con la figura del entorno, protegiendo las cuencas visuales desde los megalitos.

La protección de este conjunto patrimonial supone un avance sustancial que permite dotarlo de un régimen efectivo de tutela, a través del control y supervisión por parte de las administraciones competentes de los proyectos y actuaciones que se programen o desarrollen en las áreas delimitadas. Esta decisión supone además el reconocimiento de 
los valores patrimoniales de este territorio y del conjunto de sitios arqueológicos, y refuerza la apuesta por convertir el patrimonio histórico en una estrategia de futuro para un territorio en regresión demográfica, económica y social; una apuesta que no se limita al patrimonio histórico, sino que pretende incluir otros ámbitos como el geológico a través del proyecto de declaración de esta comarca como Geoparque de la UNESCO (Arribas et al., 2017). Nos encontramos así en una coyuntura en la que esta comarca, integrante de eso que se viene denominando la España vaciada, apuesta por su patrimonio territorial como recurso endógeno para su futuro; el patrimonio arqueológico del río
Gor, con su dimensión territorial y paisajística, debe ser eje fundamental en esta estrategia, y su protección patrimonial como BIC no sólo resulta ineludible para garantizar la conservación de sus valores, sino que puede suponer una vía para el acceso a nuevas fuentes de financiación y recursos.

La inscripción del BIC, con toda su importancia, no supone el punto final de un proceso; al contrario, es el inicio para una nueva etapa en la que debe abordarse la gestión de los bienes protegidos; esta cuestión, si bien no es objeto de este artículo, merece algunas consideraciones, ya expuestas con más detalle en trabajos previos (Montufo, 2017a).

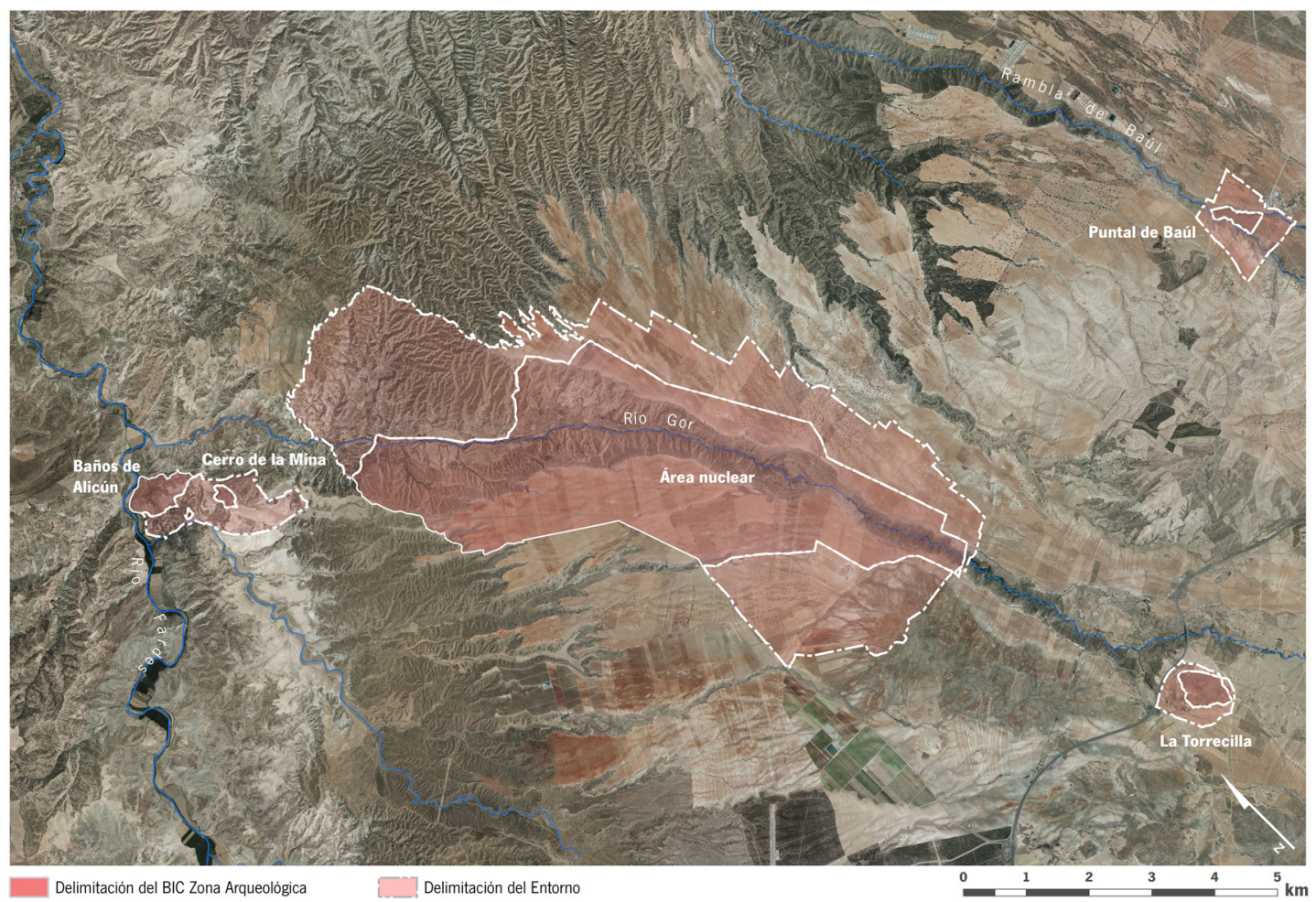

Figura 13: delimitación del BIC del Paisaje Megalítico del río Gor. Cartografía base: Ortofotos PNOA máxima actualidad (Fuente: elaboración propia).

De entrada, cabe señalar que la legislación patrimonial basa su acción tutelar en la técnica de la autorización previa por la administración competente de los proyectos y actuaciones que se planteen en los ámbitos protegidos. Esta técnica, presente ya en disposiciones legislativas como el Real Decreto-Ley de 1926, es la que establecen las leyes de patrimonio vigentes, tanto a nivel estatal (artículos 19 y 20 de la Ley 16/1985) como en Andalucía (Artículos 33 y 34 de la Ley 14/2007).
Por otro lado, la legislación patrimonial, consciente de la necesidad de hacer más operativa la gestión de los bienes culturales, prevé otros mecanismos entre los que destaca el planeamiento urbanístico, al que se otorga un rol determinante al entender que ofrece los instrumentos más adecuados para materializar las determinaciones necesarias para la protección de los bienes culturales (Barrero Rodríguez, 2007; Becerra García, 
2010; Montufo Martín, 2017a). En consonancia con este rol, se llega incluso a contemplar la eliminación del requisito de la autorización patrimonial previa cuando el planeamiento cuente con las necesarias medidas de protección.

No obstante, la redacción y aprobación de estos planeamientos de protección no ha alcanzado el desarrollo que cabría esperar habida cuenta de los beneficios que ofrece para la gestión de los bienes culturales. Entre los factores que han frenado estos instrumentos se puede citar la complejidad técnica de estos documentos, los problemas presupuestarios para su redacción o la escasa capacidad de gestión en los ayuntamientos de menor tamaño (Becerra García, 2000; Isac Martínez de Carvajal 2010).

En el caso de Andalucía, la LPHA prevé un instrumento adicional, las denominadas instrucciones particulares, que "concretan, para cada bien y su entorno, la forma en que deben materializarse las obligaciones previstas en esta ley" (artículo 11 de la LPHA); de esta forma, se pueden establecer condiciones específicas para la tutela, acordes con las particularidades de cada bien, lo que redunda en una mejor gestión.

Una vez materializada la protección patrimonial del Paisaje Megalítico del río Gor, desde la Consejería de Cultura y Patrimonio Histórico se avanza en la redacción de las instrucciones particulares que permitan establecer los parámetros de ordenación y gestión del espacio protegido desde la perspectiva de la protección patrimonial, teniendo en cuenta que en este caso lo patrimonial abarca de forma expresa al paisaje y al territorio. Su aprobación permitirá articular un marco de gestión optimizado, en el que se pueda establecer la innecesariedad de la autorización previa para todas aquellas actividades que no causen impactos patrimoniales, precisar las condiciones de autorización para otras tantas o establecer una zonificación de los ámbitos protegidos en función de variables como la caracterización patrimonial, los usos del suelo y actividades dominantes, en las que se establezcan condiciones específicas de gestión.

\section{Conclusiones}

El proyecto que hemos desarrollado ha permitido establecer una protección patrimonial, con la categoría de BIC y la tipología de Zona Ar- queológica, para un extenso territorio, caracterizado por la singular asociación entre uno de los más espectaculares complejos megalíticos de Europa occidental y un área geográfica de gran personalidad, con accidentes tan destacados como el gran cañón del río Gor o las zonas de badlands.

Esta realidad patrimonial nos ha convencido de la necesidad de aplicar criterios territoriales y paisajísticos, no sólo a nivel operativo como instrumentos para la delimitación del BIC, sino también a nivel conceptual, al asumir que esta dimensión cualifica y singulariza este conjunto patrimonial. La perspectiva territorial y paisajística no se limita, en nuestro caso, a mero discurso teórico, sino que se convierte en criterio que, junto a otros, caracteriza el ámbito analizado como realidad patrimonial, justifica su protección administrativa y vertebra su delimitación.

La elección, consciente y explícita, de una perspectiva paisajística ha tenido su correlato en la metodología aplicada para la identificación y delimitación de los ámbitos patrimoniales a proteger. Desde este planteamiento teórico, el trabajo de delimitación sólo podía abordarse a través de metodologías e instrumentos de carácter territorial, entre los que destaca el empleo sistemático y exhaustivo de SIG, tanto para representar cartográficamente el territorio como para desarrollar técnicas de análisis que permitiesen identificar los ámbitos paisajísticamente significativos en relación con los megalitos y demás sitios arqueológicos.

Los resultados alcanzados se materializan en la protección de una Zona Arqueológica que abarca un territorio de $40 \mathrm{~km}^{2}$, sumando los ámbitos BIC y los del entorno, y que engloba una diversidad de ambientes territoriales y patrimoniales. La aplicación de los criterios e instrumentos analizados en las páginas precedentes ha permitido identificar de forma nítida los ámbitos significativos a nivel patrimonial y justificar la delimitación propuesta a la luz de los criterios citados.

La delimitación de una extensa Zona Arqueológica, en la que conviven áreas en las que no existen, de forma directa, registros arqueológicos, supone una apuesta por proteger no sólo la "materialidad" del registro arqueológico conservado, sino un contexto territorial intrínsecamente vinculado a la implantación de este registro y cuya enhebración generó un auténtico paisaje megalítico, reconocible de alguna forma aún hoy día. $\mathrm{La}$ 
Zona Arqueológica del Paisaje Megalítico del río Gor supone así la plasmación en la tutela patrimonial de los criterios territoriales y paisajísticos que desde la investigación prehistórica se han señalado como claves para entender el megalitismo.

No cabe duda de que la decisión por la protección patrimonial de este paisaje arqueológico se ha visto favorecida por una serie de circunstancias que minimizan los posibles conflictos en la tutela, que emergen de forma ineludible ya que esta supone el sometimiento de intereses y expectativas particulares al interés general. En nuestro caso, somos conscientes de que la realidad territorial existente, la de un ámbito rural y agrario escasamente urbanizado, en el que no existen expectativas de desarrollos urbanísticos o proyectos transformadores de los usos del suelo a gran escala, hace que una protección patrimonial como la establecida genere, al menos potencialmente, una menor conflictividad.

La concienciación social e implicación de la población y las instituciones locales con la protección del patrimonio arqueológico es otro de los elementos que no debemos dejar de señalar como factores que confluyen para el éxito de esta propuesta de protección patrimonial. Esta doble conciencia y apuesta, tanto institucional como democrática, ha permitido la conservación del patrimonio megalítico hasta nuestros días, y debe constituir una de las claves para abordar la tutela efectiva de este BIC.

\section{Agradecimientos}

Este artículo surge a partir de un proyecto desarrollado en el seno de la Consejería de Cultura; como tal, el primer agradecimiento debe ser para mis compañeros de la Delegación Territorial de Cultura en Granada y del Servicio de Protección del Patrimonio Histórico de la Dirección General de Bienes Culturales, con los que he compartido numerosas reflexiones al hilo de este y otros expedientes. Gonzalo Aranda, Fernando Molina, Narciso Zafra y Alicia Ruiz hicieron valiosas aportaciones al borrador del artículo. Finalmente, agradezco las sugerencias de los evaluadores anónimos, que han contribuido a mejorar este trabajo. No obstante, todas las consideraciones que se expresan son de mi total responsabilidad.

\section{Bibliografía}

Afonso Marrero, J. A.; Cámara Serrano, J. A.; Haro, M.; Molina González, F.; Montufo Martin, A. M.; Sánchez, I.; Spanedda, L. (2006): "Organización territorial en el valle del Río Gor en la Prehistoria", Simbolismo, Arte e Espaços Sagrados na Pré-história da Península Ibérica. Actas do IV Congresso de Arqueologia Peninsular. Faro, setembro de 2004 (Bicho, N., de.), Universidade do Algarve, Faro, pp. 39-52.

Afonso Marrero, J. A.; Cámara Serrano, J. A.; Haro, M.; Molina González, F.; Montufo Martin, A. M.; Salas Herrera, F., Sánchez Jiménez, I; Spanedda, L. (2008): “Tipología y seriación en el megalitismo granadino: el caso de Gorafe", Actas de IV Congreso del Neolítico Peninsular. Alicante, 27-30 de noviembre de 2006 (Hernández Pérez, M., Soler Díaz, J. y López Padilla, J., Eds.) pp. 64-76.

Aranda Jiménez, G.; Lozano Medina, A. (2014): "The chronology of megalithic funerary practices: a Bayesian approach to Grave 11 at El Barranquete necropolis (Almería, Spain)", Journal of Archaeological Science, 50, 369-382.

Aranda Jiménez, G.; Lozano Medina, A.; Díaz-Zorita Bonilla, M.; Sánchez Romero, M.; Escudero Carrillo, J. (2018a): "Cultural Continuity and Social Resistance: The Chronology of Megalithic Funerary Practices in Southern Iberia", European Journal of Archaeology, 21(2), 192-216.

Aranda Jiménez, G.; Lozano Medina, A., Sánchez Romero, M., Díaz-Zorita Bonilla, M.; Bocherens, H. (2018b): "Chronology of Megalithic Funerary Practices in Southeastern Iberia: The Necropolis of Panoria (Granada, Spain)", Radiocarbon, 60 (1), pp. 1-19.

Arribas, A.; Garrido, G.; Lorenzo, C.; Garrido, J. A. (2017): "El valle del río Fardes y la Estación paleontológica de Fonelas: un laboratorio del Cuaternario", Enseñanza de las Ciencias de la Tierra, 25 (1), pp. 82-87.

Barrero Rodríguez, M. C. (2007): "Las innovaciones de la Ley 14/2007, de 26 de noviembre, del Patrimonio Histórico de Andalucía en la ordenación urbanística de los conjuntos históricos", Administración de Andalucía. Revista Andaluza de Administración Pública, 68, pp. 73-111. 
Becerra García, J. M. (2000): "El planeamiento como instrumento para la protección de los conjuntos históricos", PH. Boletín del Instituto Andaluz del Patrimonio Histórico, 30, pp. 113-116.

Becerra García, J. M. (2010): "El patrimonio histórico y planeamiento urbanístico en Andalucía", El Nuevo Marco Legal del Patrimonio Histórico Andaluz (J. M. Becerra García, Coord.), Sevilla: Instituto Andaluz de la Administración Pública, pp. 31-54.

Botella López, M. (1980): "Excavaciones arqueológicas en el pueblo eneolítico de las Angosturas en Gor", Boletín de la Diputación Provincial de Granada, 1, pp. 27-28.

Castellanos, M.; Fresneda, E.; López López, M.; Peña, J. M.; Buendía, A. F. (2001): "El paisaje megalítico de Gorafe (Granada. España). Parque temático integral sobre el megalitismo en Gorafe (Granada. España). Primera fase de actuación: Majadillas. Llanos de Olivares y Hoyas del Conquín”, Territorios megalíticos del Mediterráneo. Gorafe (Granada. España). Sa Corona Arrùbia (Cagliari. Cerdeña. Italia), pp. 3-68, Líder Comarca de Guadix S.L., Granada.

De La Cruz, J.; Yanes, M.; Sánchez, C.; Simón, M. (2006): Altiplano Estepario. Ambientes Semiáridos del Sureste Andaluz. Consejería de Medio Ambiente. Junta de Andalucía.

Diaz-Guardamino, M.; García Sanjuan, L.; Wheatley, D. - Coords. - (2015). The Lives of Prehistoric Monuments in Iron Age, Roman, and Medieval Europe. Oxford University Press, Oxford.

Escoriza Mateu, T. (1990): "Ídolos de la Edad del Cobre del yacimiento de Las Angosturas (Gor, Granada)", Zephyrus, XLIII, pp. 95-100.

Fábrega Álvarez, P. y Parcero-Oubiña, C. (2019): "Now you see me. An assessment of the visual recognition and control of individuals in archaeological landscapes", Journal of Archaeological Science, 104, pp. 56-74

Ferrer Palma. J. (1981): Los sepulcros Megaliticos de la Provincia de Granada. Tesis Doctoral: Universidad de Granada.

García Sánchez, M. (1961): "Restos humanos eneolíticos procedentes de los dólmenes de Gorafe (Granada)", Archivo de Prehistoria Levantina, IX, pp. 49-78.

García Sánchez, M. (1963): "El poblado argárico del Cerro del Culantrillo, en Gorafe (Granada)", Archivo de Prehistoria Levantina, X, pp. 69-96.

García Sánchez, M. y Spahni, J.C. (1958): “Grabados rupestres esquemáticos de época eneolítica en Baños de Alicún (Granada)", Archivo de Prehistoria Levantina, VII, pp. 121-133.

García Sánchez, M. y Spahni, J.C. (1959): "Sepulcros megalíticos de la región de Gorafe (Granada)", Archivo Prehistórico Levantino, VIII, pp. 43-123.

García Sanjuán, L. y Ruiz González, B. -Eds.- (2009): Las grandes piedras de la Prehistoria. Sitios y paisajes megalíticos de Andalucía, Junta de Andalucía. Consejería de Cultura, Sevilla.

García Sanjuán, L.; Metcalfe-Wood, S.; Rivera Jiménez, T.; Wheatley, D.W. (2006): “Análisis de pautas de visibilidad en la distribución de monumentos megalíticos de Sierra Morena Occidental”, La Aplicación de los SIG en Arqueología del Paisaje (I. Grau Mira, Ed.), Serie Arqueología, Publicaciones de la Universidad de Alicante, Alicante, pp. 181-200.

García Sanjuán, L.; Wheatley, D.W.; Murrieta Flores, P.; Márquez Pérez, J. (2009): "Los SIG y el análisis espacial en Arqueología. Aplicaciones en la Prehistoria Reciente del sur de España", Arqueologia Nàutica Mediterrània (X. Nieto, M.Á. Cau, Eds.), Monografies del CASC 8, Museu d'Arqueologia de Catalunya. Centre d'Arqueologia Subaquàtica de Catalunya, Girona, pp. 163-180.

García Sanjuán, L.; Moreno Escobar, M.C.; Márquez Pérez, J.; Wheatley, D. (2016): "The Copper Age in the lands of Antequera (Málaga): introduction to the settlement patterns and social dynamics", Zephyrus, 77, 35-65.

Góngora y Martínez, M. (1868): Antigüedades Prehistóricas de Andalucía, Imprenta a cargo de C. Moro, Madrid. (online en http://www.bibliotecavirtualdeandalucia.es/catalogo/es/consulta/registro. cmd?id=7965)

Gonçalves, V. -Ed.-(2000): Muitas antas, pouca gente? Actas do Colóquio Internacional sobre Megalitismo. Trabalhos de Arqueologia, 16, Instituto Português De Arqueologia, Lisboa.

Hoskin, M.; Allan, E.; Gralewsky, R. (1994): "Studies in Iberian Archaeoastronomy: orientations of the sepulcres of Almería, Granada and Málaga”, Archaeoastronomy, 19, pp. 555-582.

Isac Martínez De Carvajal, A. (2010): "La protección del patrimonio y el planeamiento urbano en la Ley del Patrimonio Histórico Andaluz de 2007”, La Protección del Patrimonio Histórico en la España Democrática (I. Henares Cuéllar, Ed.). Granada: Universidad de Granada, pp. 215-232

Leisner, G. y Leisner, V. (1943): Die megalithgräber der Iberischen Halbinsel: Der Süden, Verlag von Walter De Gruyter \& Co, Berlin. 
López López, M. y Castellano, M. (2001): "Evolución del paisaje megalítico en el valle del Río Gor", Aspetti del megalitismo preistorico (Serrelli G. y Vacca, D., cur.), Operatore Collettivo Sa Corona Arrubia/GAL Comarca de Guadix, Cagliari, pp. 71-78.

López Marcos, A. y Cifuentes Martínez, C. (2010): Dictamen sobre el Paisaje Cultural de Gorafe. Instituto Andaluz del Patrimonio Histórico (inédito).

Lorrio, A. y Montero Ruiz, I. (2004): "Reutilización de sepulcros colectivos en el Sureste de la Península Ibérica: la colección Siret", Trabajos de Prehistoria, 61 (1), pp. 99-116.

Lozano Medina, A. y Aranda Jiménez, G. (2017): "La temporalidad de las sepulturas megalíticas tipo tholos del sur de la Península Ibérica". SPAL, 26, pp. 17-31.

Llobera, M. (2006): “Arqueología del paisaje en el siglo XXI: reflexiones sobre el uso de los SIG y modelos matemáticos", La aplicación de los SIG en la arqueología del paisaje (Grau Mira, I., Ed.), pp. 109-124.

Manarqueoteca, S.L. (2001): "Guía del Parque Temático Integral sobre el Megalitismo en Gorafe (Granada, España)", Parque Temático sobre el Megalitismo. Gorafe (Granada, España), Sa Corona Arrùbia (Cagliari, Cerdeña, Italia). Guía (AA.VV.), Líder Comarca de Guadix S.L., Granada, pp. $32-135$.

Manrique López, J. J. (2008): "Parque Arqueológico del Megalitismo en Gorafe", Patrimonio megalítico: más allá de los límites de la Prehistoria, PH, 67 Especial Monográfico, pp. 166-170.

Martín De La Cruz, J.C., Bermúdez Sánchez, J.; Perlines Benito, M. (2004): "Los SIG aplicados a la campiña de Córdoba: diacronías y sincronías poblacionales", Actas del I Encuentro Internacional Informática Aplicada a la Investigación y Gestión Arqueológicas (Martín de la Cruz, J. C. y Lucena Martín, A., Coords.), Universidad de Córdoba, Córdoba, pp. 211-238.

Martínez García, J. (1995): "Grabados prehistóricos, grabados históricos. Reflexiones sobre un debate a superar", Revista de Arqueología, 172, pp. 14-23.

Martinón Torres, M. (2001): "Los megalitos de término. Crónica del valor territorial de los monumentos megalíticos a partir de las fuentes escritas", Trabajos de Prehistoria, 58 (1), pp. 95-108.

Molina González, F. (1983): "Prehistoria", Historia de Granada I. De las primeras culturas al Islam, (Molina González, F. y Roldán Hervás, J.M.). Don Quijote, Granada, pp.

Montufo Martín, A. M. (2017a): "La protección patrimonial del territorio. Teorías, Conceptos Normativos y Casos de Estudio en Granada", E-RPH. Revista electrónica de Patrimonio Histórico, 20, pp. 5-56.

Montufo Martín, A. M. (2017b): Documentación Técnica para la Inscripción en el CGPHA del Paisaje Megalítico del Río Gor como Bien de Interés Cultural con la tipología de Zona Arqueológica. Consejería de Cultura (inédito).

Montufo Martín, A. M., Cámara Serrano, J. A.; Afonso Marrero, J. A.; Molina González, F. (2010). "Visibility and monumentality in Late Prehistory graves of western Granada. A GIS analysis", Links between Megalithism and Hypogeism in Western Mediterranean Europe (Cámara Serrano, J., Afonso Marrero, J., y Spanneda, L., Eds.) BAR International Series, 2151, pp. 29-51.

Montufo Martín, A. M.; Cámara Serrano, J. A.; Afonso Marrero, J. A.; Molina González, F.; Spanneda, L. (2011): "Relaciones visuales entre los yacimientos arqueológicos prehistóricos de las Peñas de los Gitanos (Montefrío, Granada). Estrategias de ocultación, control del espacio productivo y límites, Antiquitas, 23, pp. 73-85.

Murrieta-Flores, P. (2014): "Developing computational approaches for the study of movement: assessing the role of visibility and landscape markers in terrestrial navigation during Iberian late prehistory", Computational approaches to movement in archaeology. Theory, practice and interpretation of factors and effects of long term landscape formation and transformation (Polla, S. y Verhagen, P., Eds.), pp. 99-132.

Murrieta-Flores, P.; García Sanjuán, L.; Wheatley, D. (2011): “Antes de los mapas: navegación y orientación terrestre en la Prehistoria Reciente Ibérica", $P H, 77$, pp. 85-88.

Nocete Calvo, F. (1996): "Un modelo de aplicación de análisis multivariante a la prospección arqueológica: la definición de la unidad geomorfológica donde se establece el asentamiento", Arqueología Espacial, 15 , pp. 7-35.

Pérez Álvarez, J.; Bascón Arroyo, F.; Crespo Pérez, F. J.; Charro Lobato, M. C. (2013): "Project Casey Jones, 1945-46: el vuelo histórico fotogramétrico de la Serie A", Mapping, 159, pp. 14-24.

Renfrew, C. (1973): Before Civilization: The Radiocarbon Revolution and Prehistoric Europe, Alfred Knopf, New York.

Ruggles, C.; Medyckyj-Scott, D. J.; Gruffydd, A. (1993): "Multiple viewshed analysis using GIS and its archaeological application: a case study in northern Mull", Computing the Past, Computer Applications 
in Archaeology 1992 (Andresen, J., Madsen, T. y Scollar, I., Eds.), pp. 125-132. Aarhus University Press, Aarhus.

Ruiz González, B. -Dir. - (2018): Plan Director del Conjunto Arqueológico Dólmenes de Antequera. 2018/2025. Junta de Andalucía.

Sanchez Quirante, L. (1992): "Prospección arqueológica superficial del sector occidental de la Sierra de Baza. Campaña de 1990", Anuario Arqueológico de Andalucía 1990, 2, pp. 124-127.

Siret, L. (2001): España Prehistórica. 1891-2001. Junta de Andalucía, Consejería de Cultura, Sevilla

Wheatley, D. W. (1995): "Cumulative viewshed analysis: A GIS-based method for investigating intervisibility and its archaeological application", Archaeology and Geographical Information Systems: A European Perspective (Lock, G. y Stancic, Z., Eds.), Taylor \& Francis, London, pp. 171-185.

Wheatley, D. W. (1996): "The use of GIS to understand regional variation in earlier Neolithic Wessex", New Methods, Old Problems. Geographic Information Systems in Modern Archaeological Research (Maschner, H., Ed.), Centre for Archaeological Investigations Carbondale, pp. 75-103.

Wheatley, D. W.; Murrieta Flores, P. (2009): "Grandes piedras en un mundo cambiante: la arqueología de los megalitos en su paisaje", PH, 67, pp. 24-33.

Wheatley, D. W.; García Sanjuán, L.; Murrieta Flores, P.; Márquez Pérez, J. (2010): “Approaching the landscape dimension of the megalithic phenomenon in southern Spain", Oxford Journal of Archaeology, 29 (4), pp. 387-405.

\section{Notes}

1. Paseo de la Bomba 11, Granada 18008. Consejería de Cultura y Patrimonio Histórico. Delegación Territorial de Granada antoniom.montufo@juntadeandalucia.es

2. Real Orden de 1 de junio de 1886 (Ruiz González, 2018:26).

3. Ley de 7 de julio de 1911, estableciendo las reglas a que han de someterse las excavaciones artísticas y científicas y la conservación de las ruinas y antigüedades. (Gaceta de Madrid n ${ }^{\circ} 189$, de 8 de julio).

4. La legislación sobre patrimonio histórico del siglo XX concibe el corpus de bienes patrimoniales de forma unitaria, sin que se reconozcan las particularidades de los denominados "patrimonios especiales", que adquirirán carta de naturaleza en la Ley 16/1985, en la que se dedican títulos específicos para el patrimonio arqueológico o el etnográfico y establece en consecuencia tipologías específicas dentro de la figura del Bien de Interés Cultural, como las Zonas Arqueológicas o los Sitios Históricos

5. Gaceta de Madrid $\mathrm{n}^{\circ} 145$, de 25 de mayo de 1933.

6. Resolución de 24 de noviembre de 1980, de la Dirección General de Bellas Artes, Archivos y Bibliotecas $\left(\mathrm{BOE} \mathrm{n}^{\circ} 22\right.$, de 26 de enero de 1981).

7. Decreto 72/1993, de 25 de mayo, por el que se declara Bien de Interés Cultural, con la categoría de Zona Arqueológica, el yacimiento denominado Loma de Galera, en el término municipal de Alhama de Almería (Almería) (BOE $n^{\circ} 163$, de 9 de julio).

8. Decreto 194/2007, de 26 de junio, por el que se declara Bien de Interés Cultural, con la categoría de Zona Arqueológica, el Yacimiento Arqueológico denominado Necrópolis Megalítica de Gádor (Almería). (BOJA n ${ }^{\circ} 132$, de 5 de julio). Bajo esta denominación se integran varios conjuntos megalíticos, en concreto los de Rambla de Las Balsas, Llanos de Retamar, Tajos Coloraos, Collado Ceporro I y II, Jacalgarín, Cuesta del Rayo, La Corraliza, Llanos de Regina, Rambla de Ciscarejo, Gádor, Rambla de Jalbos I y II, Marchal de Araoz, Rambla de Las Pocitas, y Loma de Los Mudos I y II.

9. Este fenómeno dista de ser exclusivo del valle del río Gor, a este respecto resulta muy ilustrativo el título del I Colóquio Internacional sobre Megalitismo celebrado en Reguengos de Monsaraz (Portugal) en 1996 "Muitas antas, pouca gente" (Gonçalves, 2000).

10. El número de sepulturas excavadas por Pedro Flores y Luis Siret es un dato sobre el que la bibliografía ofrece cierta controversia: Georg y Vera Leisner afirman que Siret identificó 144 megalitos (Leisner y Leisner, 1943:85), mientras que Manuel García Sánchez y Jean C. Spanhi (1959:44) elevan esa cifra a 
166. Los cuadernos de campo de Pedro Flores, conocidos como "Cuadernos de Campo de numeración árabe" y consultables en la Web del Museo Arqueológico Nacional, citan, según mi investigación, un total de 113 sepulturas.

11. En relación con esta afirmación, debemos señalar cómo los trabajos realizados para la redacción del expediente de inscripción en el CGPHA del Paisaje Megalítico del río Gor nos han permitido localizar varias estructuras inéditas en el corpus de Manuel García Sánchez y Jean C. Spahni y que pudieron ser excavadas por Pedro Flores.

12. Un problema similar ya fue detectado por Georg y Vera Leisner al revisar la documentación de Luis Siret y comprobar la dificultad para correlacionar las sepulturas debido a los cambios en la parcelación y la microtoponimia (Leisnes y Leisner, 1943:85).

13. Además de esta conocida serie, la fuerza aérea estadounidense realizó un primer vuelo cartográfico entre 1946-46, conocido como "serie A". A pesar de su innegable interés, este proyecto empleó cámaras no métricas y el material elaborado ha sufrido una serie de vicisitudes (mala ejecución de los vuelos, pérdida de fotogramas, mala conservación, etc.) que hace que actualmente no se ha haya podido elaborar una ortofotografía derivada de este vuelo (más detalles técnicos en Pérez Álvarez et al., 2013).

14. Decreto 43/2018, de 20 de febrero, por el que se inscribe en el Catálogo General del Patrimonio Histórico Andaluz, como Bien de Interés Cultural, con la tipología de Zona Arqueológica, el Paisaje Megalítico del río Gor en los términos municipales de Gor, Gorafe, Villanueva de las Torres, Guadix y Baza (Boja $n^{\circ} 40$, de 26 de febrero). 